\title{
Chimeric antigen receptor T-cells for B-cell malignancies
}

\author{
EBEN I. LICHTMAN, and GIANPIETRO DOTTI
}

CHAPEL HILL, NC

\begin{abstract}
The adoptive transfer of T-lymphocytes modified to express chimeric antigen receptors (CAR-Ts) has produced impressive clinical responses among patients with B-cell malignancies. This has led to a rapid expansion in the number of clinical trials over the past several years. Although CD19-specific CAR-Ts are the most extensively evaluated, CAR-Ts specific for other B-cell-associated targets have also shown promise. However, despite this success, toxicities associated with CAR-T administration remain a significant concern. There continues to be substantial heterogeneity among CAR-T products, and differences in both CAR designs and CAR-T production strategies can substantially affect clinical outcomes. Ongoing clinical studies will further elucidate these differences and many other innovative approaches are being evaluated at the preclinical level. In this review, we will discuss the background and rationale for the use of CAR-Ts, provide an overview of advances in the field, and examine the application of CAR-Ts to the treatment of B-cell malignancies, including a summary of clinical trials published to date. (Translational Research 2017; 187:59-82)
\end{abstract}

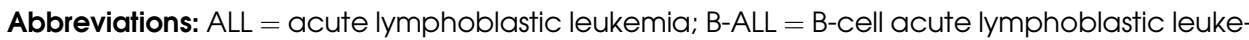
mia; CAR-T = chimeric antigen receptor T-cell; CAR = chimeric antigen receptor; $C D=$ cluster of differentiation; $\mathrm{CHOP}=$ Children's Hospital of Philadelphia; $\mathrm{CLL}=$ chronic lymphocytic leukemia; $\mathrm{CR}=$ complete remission or complete response; CRISPR-Cas9= clustered regularly interspaced short palindromic repeats CRISPR-associated protein 9; CRS = cytokine release syndrome; CTLA-4 = cytotoxic T-lymphocyte-associated protein 4; DLBCL = diffuse large B-cell lymphoma; DNA = deoxyribonucleic acid; FHCRC = Fred Hutchinson Cancer Research Center; $\mathrm{FL}=$ follicular lymphoma; $\mathrm{HIV}=$ human immunodeficiency virus; $\mathrm{iC9}=$ inducible caspase-9; IFN $\gamma=$ interferon gamma; IL = interleukin; ITAM = immunoreceptor tyrosine-based activation motif; JAK/STAT = Janus kinase/signal transducers and activators of transcription; $\mathrm{MCL}=$ mantle cell lymphoma; $\mathrm{MHC}=$ major histocompatibility complex; $\mathrm{MRD}=$ minimal residual disease; $\mathrm{mRNA}=$ messenger ribonucleic acid; $\mathrm{MSKCC}=$ Memorial Sloan Kettering Cancer Center; $\mathrm{NCl}=$ National Cancer Institute; $\mathrm{NHL}=$ non-Hodgkin lymphoma; ORR = overall response rate; PBMCs = peripheral blood mononuclear cells; PD- 1 = programmed cell death protein $1 ; \mathrm{PR}=$ partial remission or partial response; $\mathrm{SCFv}=$ single-chain variable fragment; TALEN = transcription activator-like effector; TBI = total body irradiation; TCR $=$ T-cell receptor; $\mathrm{TM}=$ transmembrane; ZFN = zinc-finger nuclease
\end{abstract}

From the Department of Medicine, University of North Carolina, Chapel Hill, NC; Lineberger Comprehensive Cancer Center, University of North Carolina, Chapel Hill, NC; Department of Microbiology and Immunology, University of North Carolina, Chapel Hill, NC.

Submitted for publication March 17, 2017; revision submitted May 18, 2017; accepted for publication June 23, 2017.
Reprint requests: Eben I. Lichtman, Division of Hematology/ Oncology, Department of Medicine, University of North Carolina, 170 Manning Drive, CB\#7305, Chapel Hill, NC, 27599; e-mail: eben.lichtman@unchealth.unc.edu.

http://dx.doi.org/10.1016/j.trs1.2017.06.011 


\section{INTRODUCTION}

The adoptive transfer of chimeric antigen receptor Tcells (CAR-Ts) has emerged as an extremely promising immunotherapeutic approach for the treatment of B-cell malignancies, and the remarkable versatility of this technique makes it potentially applicable to a wide range human diseases. Traditional CAR molecules couple the single-chain variable fragment $(\mathrm{scFv})$ of a monoclonal antibody to one or more intracellular signaling domains derived from the T-cell receptor (TCR) complex and costimulatory molecules. When stably expressed on the surface of T-cells, CARs combine the antigen-binding properties of a monoclonal antibody with the effector and self-renewal properties of T-lymphocytes. The native TCR recognizes intracellular peptide antigens that are presented on the cell surface by the major histocompatibility complex (MHC). Because of the highly polymorphic nature of the MHC gene, a TCR specific for a given peptide-MHC complex would be unlikely to recognize the same antigen when presented by another patient's MHC. In contrast, the $\mathrm{scFv}$ of a CAR targets antigens directly expressed on the surface of tumor cells (without processing and $\mathrm{MHC}$ presentation), allowing the same receptor to be used for all patients. Furthermore, in addition to proteins, the $\mathrm{scFv}$ of a CAR can also recognize carbohydrates and glycans, thereby greatly expanding the array of targetable antigens. Finally, the MHC-independent recognition of targeted antigens by CAR-Ts overcomes one of the major mechanisms of tumor escape, that is, the downregulation of $\mathrm{MHC}$ on tumor cells.

Immune surveillance and targeted immune responses are important in both preventing and suppressing many cancers; however, tumors may ultimately escape immune recognition and destruction via multiple mechanisms. ${ }^{1-3}$ It has, therefore, been a long-standing goal to devise ways to engineer components of the immune system to overcome tumor-associated evasion and suppression strategies. Adoptively acquired immunity was first described in $1954,{ }^{4}$ and the development of allogeneic hematopoietic stem cell transplantation (HSCT) beginning in the late 1960s represented the first major breakthrough in cellular immunotherapy. The concept of CAR-Ts was described in the mid-1980s. ${ }^{5,6}$ Many technical challenges prevented early clinical application however, ${ }^{7}$ and it is only in the past 5-years that the efficacy of CAR-Ts has been demonstrated in multiple clinical trials. The past decade has also seen significant advances in other areas of cancer immunotherapy, including the emergence of immune checkpoint inhibitors and bi-specific antibodies. Taken together, these therapies have firmly established the enormous potential benefits of redirecting the immune system to target cancer cells, and the unprecedented success of CD19-directed CAR-Ts has clearly demonstrated the efficacy of adoptive cellular immunotherapies in accomplishing this goal.

\section{DEVELOPMENT OF CHIMERIC ANTIGEN RECEPTORS}

First-generation CARs. The native TCR is a membrane-bound heterodimer comprised of an $\alpha$ chain and a $\beta$-chain. Antigen recognition by the endogenous TCR of $\mathrm{CD}^{+}$and $\mathrm{CD} 8^{+}$T-cells is restricted to peptides bound to polymorphic MHC molecules on the surface of cells. Recognition of an MHC-bound peptide antigen by the TCR leads to downstream activation of kinase pathways via a complex of noncovalently associated transmembrane (TM) signaling molecules, including a heterodimer of $\mathrm{CD} 3 \varepsilon$ and $\mathrm{CD} 3 \delta$, a heterodimer of $\mathrm{CD} 3 \varepsilon$ and $\mathrm{CD} 3 \gamma$, and a homodimer of $\zeta$-chains. TCR engagement alone is not sufficient to fully activate T-cells, however, and a requisite second activation signal is provided when a costimulatory receptor on the T-cell binds to its cognate ligand on an antigen-presenting cell. CD28 is the most well-characterized costimulatory receptor and binds to either CD80 or CD86 on the surface of antigen-presenting cells. ${ }^{8}$ CD80, CD86, and other costimulatory molecules are generally not expressed by tumor cells, however, and chronic TCR activation in the absence of costimulation (or in the presence of signaling via coinhibitory receptors such as cytotoxic T-lymphocyte-associated protein 4 and programmed cell death protein 1) leads to T-cell anergy or death. ${ }^{9,10}$

The first CARs developed in the mid-1980s consisted of the variable region of a monoclonal antibody coupled to the constant region ( $\alpha$ - and $\beta$-chains) of the TCR. ${ }^{5,6}$ The extracellular component (ectodomain) was later modified to include only a recombinant $\mathrm{scFv}$ from the antigen-binding variable domains of both the heavy and light chains of a monoclonal antibody. The scFv was coupled to a TM domain, followed by an immunoreceptor tyrosine-based activation motif (ITAM) from the TCR- $\zeta$ endodomain. Eshhar et al. initially demonstrated that this chimeric protein, which they referred to as a "T-body," could induce antigen-dependent, non-MHC-restricted T-cell activation, leading to both interleukin-2 (IL-2) secretion and target cell lysis. ${ }^{11}$ This basic structure was used in many subsequent studies and is now referred to as the first-generation CAR.

Clinical trials of first-generation CAR-Ts, initially targeting the human immunodeficiency virus ${ }^{12}$ and later targeting antigens such as carbonic anhydrase IX, CD171, folate receptor $\alpha$, and GD $2^{13-17}$ expressed in solid tumors, as well CD19 and CD20 expressed by B-cell malignancies, ${ }^{18,19}$ did not induce substantial 
clinical responses, but did serve to highlight several challenges to be considered in subsequent iterations of CAR designs. One of the most significant problems was the limited persistence of CAR-Ts after infusion. Other setbacks included unexpected on-target but off-tumor toxicities. ${ }^{15,20}$ These trials have also provided us with long-term follow-up data related to the safety of certain aspects of CAR-T generation. Most CAR-T trials published to date have utilized $\gamma$-retroviral or len-tiviral vectors to express CARs in human T-cells. Based on earlier experience in which $\gamma$-retroviral vector-based gene therapy in hematopoietic stem cells led to the development of T-cell leukemia, ${ }^{21,22}$ there has been concern that the use of such vectors could cause insertional mutagenesis in CAR-Ts as well. It is thus reassuring that long-term follow-up of patients treated with first-generation human immunodeficiency virustargeted CAR-Ts (which had much better long-term persistence than most other first-generation CARs) did not reveal any evidence of vector-induced immortalization of cells or enrichment of T-cells with CAR transgene integration near genes implicated in growth control. $^{23}$

Second- and third-generation CARs. The next stage of CAR design involved attempts to improve the activation and proliferation of CAR-Ts in vivo by the incorporation of costimulatory domains. The poor in vivo persistence of first-generation CAR-Ts was felt to be partially explained by T-cell anergy and death in the absence of costimulation. To test this hypothesis, Finney et al. designed a CAR that incorporated the CD28 cytoplasmic endodomains in tandem with the TCR- $\zeta$ endodomain. In vitro studies revealed that, in response to antigen stimulation, CAR-Ts which included the CD28 endodomain produced 20-times more IL-2 than those with the TCR- $\zeta$ endodomain alone. ${ }^{24}$ Stronger evidence supporting the benefits of incorporating the CD28 costimulatory domains was provided by a study in humans directly comparing an anti-CD19- $\zeta$ (first generation) and an anti-CD19-CD28$\zeta$ (second generation) CAR. In that study, patients with non-Hodgkin lymphoma (NHL) were simultaneously infused with both CAR-T products, and it was demonstrated that CD19-CD28- $\zeta$ CAR-Ts exhibited significantly greater expansion and persistence. ${ }^{25}$

Given promising results with the incorporation of the CD28 endodomain, alternative (or additional) signaling domains have also been evaluated. 4-1BB is a member of the tumor necrosis factor receptor family and was initially selected due to data supporting its role in preventing activation-induced death, inducing expansion of $\mathrm{CD}^{+}$cells, enhancing $\mathrm{CD} 8^{+} \mathrm{T}$-cell responses during viral infection and allograft rejection, and contributing to effective antitumor responses in animal models of cancer. ${ }^{26}$ Imai et al. demonstrated in vitro that antiCD19-4-1BB- $\zeta$ CAR-Ts exhibited significantly greater cytotoxicity toward B-lineage acute lymphoblastic leukemia (B-ALL) cells and significantly greater IL-2

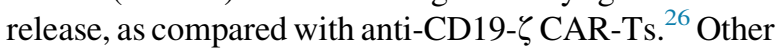
costimulatory domains (eg, OX-40) have also been evaluated. CAR constructs which add a single costimulatory domain to the first-generation backbone are known as second-generation CARs, whereas those including two costimulatory domains are referred to as thirdgeneration CARs. In addition to combining CD28 and 4-1BB, third-generation CARs have also incorporated other costimulatory domains such as OX-40. ${ }^{27,28}$ Most clinical trials conducted to date have utilized secondgeneration CARs with either a CD28 or 4-1BB costimulatory signaling domain. Although the optimal choice of costimulatory domains has not been fully elucidated, a recent study at the Baylor College of Medicine in 6 patients with diffuse large B-cell lymphoma (DLBCL) evaluated the simultaneous administration of secondgeneration CD19-specific CD28-containing CAR-Ts and third-generation CD19-specific CD28-plus 4-1BBcontaining CAR-Ts and found 23-fold (range 1.1- to 109-fold) higher expansion and correspondingly longer persistence for the third-generation CAR-Ts. ${ }^{29}$ As discussed below, there are many additional design factors that affect the function of CAR-Ts, which in addition to variable clinical trial designs, make it difficult to directly compare existing studies.

Additional design factors affecting CAR function. The potential effects of various structural modifications on CAR function have been extensively reviewed elsewhere, and a detailed discussion is beyond the scope of this article. ${ }^{20,30}$ Briefly, considerations in designing the ectodomain of a CAR include the scFv used, its affinity for the target antigen, and the specific binding site on this antigen. Although most CARs have been generated by using a $\mathrm{scFv}$, other designs have utilized single antigen-binding region domains, ${ }^{31}$ nonantibody receptors, and even ligands for another receptor. $^{32}$ The scFvs used are most commonly derived from murine monoclonal antibodies, although humanized scFvs have also been used with the goal of reducing the immunogenicity of the ectodomain. Additionally, the length of the hinge region between the scFv and the TM domain can affect the degree of T-cell activation upon antigen recognition. The TM domain itself is usually derived from the TCR- $\zeta, \mathrm{CD} 4$, $\mathrm{CD} 8$, or CD28 molecules, and the choice of TM domain can also have a significant effect on CAR-T effector function and stability. ${ }^{20}$ 


\section{PRODUCTION OF CAR T-CELLS}

Most clinical trials of CAR-Ts published to date have utilized unselected patient-derived (autologous) peripheral blood mononuclear cells, which are activated using anti-CD3 (OKT3) and anti-CD28 monoclonal antibodies (either in soluble form, immobilized, or coated to the surface of beads) ${ }^{30}$ and engineered to express the CAR transgene using viral vectors. CAR-Ts are then expanded in vitro with recombinant cytokines. ${ }^{30}$ There is significant variability in these processes between institutions, however, and the optimization of various steps involved in CAR-T production remains an area of active investigation.

Source of T-cells: allogeneic versus autologous CARs. Most reported trials of CAR-T therapy for B-cell malignancies have utilized autologous lymphocytes that have been expanded ex vivo, transduced to express a CAR transgene, and then reinfused into the patient. In the setting of prior allogeneic HSCT, several trials have also evaluated the use of allogeneic, donor-derived CD19-specific CAR-Ts in patients who have experienced, or are at high risk for experiencing, relapse of their disease. ${ }^{33-36}$ Although there are significant differences between these studies, a recent trial evaluating allogeneic CD19-specific CAR-Ts for adults with relapsed B-ALL following allogeneic HSCT demonstrated a minimal residual disease (MRD)-negative complete remission (CR) in 4 of 5 treated patients. ${ }^{34}$ In addition to this approach, there has also been substantial interest in generating allogeneic CAR-Ts which lack expression of their native TCR, thereby allowing their infusion into unrelated patients without the risk of inducing graftversus-host disease. As discussed below, the generation of so-called "universal CARs" has recently been demonstrated via the use of several novel gene-editing techniques, and the first clinical application of "universal" CD19-specific CAR-Ts was recently reported in pediatric B-ALL. 37,38

Gene transfer techniques. Most CAR-T trials to date have used either lentiviral or $\gamma$-retroviral vectors to deliver the CAR transgene into the genome of activated T-cells. Each vector allows for efficient gene delivery and contains a promoter leading to constitutive CAR expression. Although $\gamma$-retroviral vectors, when compared with lentiviral vectors, have been shown to be associated with an increased risk of insertional mutagenesis in hematopoietic stem cells, ${ }^{39}$ experience to date does not suggest any clinicallyrelevant differences between CAR-Ts produced via transduction by $\gamma$-retroviral versus lentiviral vectors, and long-term follow-up of patients treated with $\gamma$-retrovirally transduced CARs supports the safety of this technique. ${ }^{23}$ Nonviral gene transfer techniques such as the Sleeping Beauty ${ }^{35,40}$ and PiggyBac ${ }^{41}$ transposon/transposase systems are also being evaluated; however, the efficiency of DNA integration associated with these methods is generally low. Other studies have used electroporation of naked plasmid DNA; however, the efficiency of this technique is even lower. ${ }^{42}$ It is also possible to transiently express a CAR via electroporation of mRNA, which may prove to be a valuable tool to more safely investigate CAR-Ts specific for novel target antigens. Each of the above gene transfer techniques involves random insertion of the CAR transgene into the genome, and variegated transgene expression via transcriptional silencing and vector copy number variation ${ }^{43}$ has the potential to contribute to constitutive signaling and T-cell exhaustion, which could decrease CAR-T persistence in vivo. $^{44}$

Limitations of the above approaches have driven substantial interest in applying gene-editing tools such as prokaryotic type II CRISPR (clustered regularly interspaced short palindromic repeats) Cas9 (CRISPR-associated protein 9) to the generation of CAR-Ts. ${ }^{45}$ Two separate groups have recently demonstrated the use of gene-editing tools to insert a CD19-specific CAR transgene directly into the native TCR $\alpha$-chain locus, thereby simultaneously "knocking in" a CAR transgene and knocking out the endogenous TCR. ${ }^{44,46}$ Eyquem et al. $^{44}$ accomplished this using CRISPR/Cas9 geneediting techniques, and MacLeod et al. ${ }^{46}$ used an engineered homing endonuclease and an adeno-associated virus template to target a CD19-specific CAR into the TCR $\alpha$-chain locus. A potential benefit of this approach is the ability to place the CAR transgene under the control of endogenous regulatory elements, thereby potentially reducing tonic signaling and associated T-cell differentiation and exhaustion. ${ }^{44}$ To this end, Eyquem et al. demonstrated that gene-edited cells had lower but more uniform levels of CAR expression, and that these cells significantly outperformed conventional retrovirally transduced CARs in a mouse model of B-ALL. It remains to be seen whether such approaches will offer substantial clinical advantages as compared with nontargeted CAR insertion in T-lymphocytes.

Ex vivo expansion and CAR T-cell subsets. Following transduction, CAR-Ts are typically provided intermittent cytokine stimulation with the goals of both driving T-cell expansion and influencing the final composition of T-cell subsets. The differentiation status of adoptively transferred T-cells can have a profound impact on their clinical activity and persistence in vivo. Because unsorted peripheral blood mononuclear cells are usually transduced, both $\mathrm{CD} 4^{+}$and $\mathrm{CD} 8^{+}$CAR-Ts 
are simultaneously generated. Although $\mathrm{CD}^{+}$effector T-cells generally exhibit greater antitumor cytotoxicity in vitro, $\mathrm{CD}^{+}$cells may play a role in vivo in promoting the persistence of $\mathrm{CD} 8^{+} \mathrm{T}$-cells. In addition, various studies have demonstrated that the adoptive transfer of less-differentiated T-cells leads to greater persistence and antitumor efficacy in vivo. ${ }^{47-50}$ The production of CAR-Ts for clinical use has traditionally involved T-cell expansion via stimulation with recombinant IL-2. ${ }^{30}$ The cytokines IL-7 and IL-15 have subsequently been demonstrated, by our group and others, to increase the frequency of $\mathrm{CD}^{+}{ }^{+} \mathrm{CD} 45 \mathrm{RA}^{+} \mathrm{CCR}^{+} \quad$ T-cells, a phenotype corresponding to memory stem $\mathrm{T}$-cells that, when compared with more differentiated T-cell subsets, was shown to correlate with enhanced in vivo persistence and antitumor activity. ${ }^{51,52}$ Because ex vivo expansion techniques remain an active area of investigation, there is significant heterogeneity in such techniques between studies, and consequently, in the composition of T-cell subsets found in the CAR-T products administered to patients thus far.

In an approach that differs from most other trials to date, investigators at the Fred Hutchinson Cancer Research Center (FHCRC)/Seattle Children's are evaluating the utility of selecting for and purifying different T-cell subsets before transduction rather than using cytokine stimulation to drive the differentiation of unsorted T-cells. ${ }^{53-55}$ In two ongoing trials, the investigators selected $\mathrm{CD}^{+}$T-cells by positive immunomagnetic selection, selected $\mathrm{CD} 8^{+}$central memory T-cell cells by depleting $\mathrm{CD}^{+}, \mathrm{CD}^{+} 4^{+}$, and $\mathrm{CD} 45 \mathrm{RA}^{+}$cells, and then selected for $\mathrm{CD}_{2} 2 \mathrm{~L}^{+}$cells from the remaining fraction. They transduced the purified $\mathrm{CD} 4^{+} \mathrm{T}$-cells and $\mathrm{CD} 8^{+}$ central memory T-cell cells separately, expanded them in vitro, and mixed them at a specific ratio before infusing the T-cell product into patients. Although this approach seems feasible, it remains to be seen whether such techniques would be broadly applicable and if they would offer significant advantages in terms of safety and efficacy compared with the use of unselected Tcells. ${ }^{55}$

\section{ADMINISTRATION OF CAR T-CELLS}

CAR-Ts are generally administered following lymphodepletion, which has been shown to improve both CAR-T persistence and antitumor activity. ${ }^{55,56}$ The administration of either total body irradiation or preparative chemotherapy regimens was initially demonstrated to improve antitumor responses in melanoma patients treated with autologous tumorinfiltrating lymphocytes and IL-2, and this was shown to correlate with increasing circulating levels of homeostatic cytokines such as IL-7 and IL-15. . $^{56}$ Lymphodepletion is thought to directly affect the survival, persistence, and proliferation of adoptively transferred T-lymphocytes primarily via elimination of cellular elements that compete for endogenous homeostatic cytokines and by minimizing immune-mediated CAR-T rejection. ${ }^{55,56}$ The limited antitumor efficacy and CAR-T persistence seen in some early trials may be at least partially explained by the lack of adequate lymphodepletion. ${ }^{33,57}$ Most patients on recent trials have been treated with lymphodepleting chemotherapy. Although the combination of chemotherapy agents has often been left to the investigator's choice, the most common regimens have included cyclophosphamide with or without fludarabine.

The importance of adequate lymphodepletion is further emphasized by a trial conducted at FHCRC in which second-generation CD19-specific CAR-Ts were administered to adult subjects with B-ALL. The initial 13 patients received lymphodepletion with cyclophosphamide alone. Although $83 \%$ of these patients achieved a CR, $70 \%$ of them relapsed at a median of 66 days after CAR-T infusion, and this was associated with the emergence of transgene-specific cytotoxic $\mathrm{CD}^{+}$T-cell-mediated immune responses. ${ }^{55,58}$ The addition of fludarabine to the lymphodepletion regimen for the subsequent 17 patients enrolled into the study produced durable responses, with $71 \%$ of these patients remaining in $\mathrm{CR}$ at a median follow-up of 300 days. ${ }^{55}$ In a study conducted at the National Cancer Institute (NCI) of CD19-specific CAR-Ts for pediatric patients with relapsed/refractory B-ALL, Lee et al. also reported superior outcomes among patients who received lymphodepletion with fludarabine plus cyclophosphamide, compared with those receiving alternative lymphodepletion regimens (median overall survival 13.3 months versus 5.5 months, respectively). ${ }^{59}$

\section{TOXICITIES OF CAR T-CELLS}

Despite significant clinical responses across multiple clinical trials, the widespread use of CAR-T therapy has thus far been prevented by both observed and theoretical toxicities, including cytokine release syndrome (CRS), neurotoxicity, and on-target off-tumor effects. ${ }^{60}$

Cytokine release syndrome and neurotoxicity. Cytokine release syndrome is the most common and often the most severe toxicity of CAR-T therapy in patients with lymphoid malignancies, and is characterized by increased levels of multiple pro-inflammatory cytokines, including IL-6, interferon-gamma, tumor necrosis factor, IL-2, IL-2-receptor- $\alpha$, IL-8, and IL-10 ${ }^{60}$ CRS can affect multiple organs, and can occur anywhere from hours to more than 7 days following 
CAR-T infusion. Mild cases of CRS produce flu-like symptoms; however, more severe cases may lead to hypotension, vascular leak, respiratory failure due to pulmonary edema and/or pneumonitis, renal insufficiency, and neurologic complications including delirium, hallucinations, ataxia, aphasia, and seizures. ${ }^{60}$ Multiple CRS grading systems have been proposed, ${ }^{61-63}$ complicating the direct comparison of CRS cases between trials. Of note, the Common Terminology Criteria for Adverse Events, Version 4.0 $0^{64}$ criteria for grading CRS is applicable only to infusion reactions caused by monoclonal antibodies, and does not apply to adoptive cellular immunotherapy. ${ }^{60}$ Brudno and Kochenderfer have recently published guidelines for managing patients with CRS and other toxicities associated with CAR-Ts. ${ }^{60}$ Tocilizumab, a monoclonal antibody targeting the interleukin-6 receptor (IL-6R), is recommended for the initial treatment of CRS, with corticosteroids used for cases refractory to tocilizumab, and dexamethasone is specifically recommended for grade $\geq 3$ neurologic toxicities. $^{60}$ Corticosteroids may impair CAR-T expansion and persistence, and are thus avoided in milder cases of CRS. ${ }^{63,65}$ Although not yet evaluated in clinical trials, recent preclinical studies have suggested a potential benefit of the Bruton's tyrosine kinase inhibitor, ibrutinib, and the JAK/STAT pathway inhibitor, ruxolitinib, in reducing CAR-T-mediated cytokine release and preventing CRS. ${ }^{66,67}$ Despite the use of tocilizumab and corticosteroids, severe CRS has led to several deaths in clinical trials of CD19-specific CAR-Ts, and 5 deaths due to unexpected severe neurologic toxicity recently prompted the discontinuation of a large phase II clinical trial in adult subjects with relapsed/refractory B-ALL. ${ }^{55,68-70}$ Although neurotoxicity is frequently seen in the context of CRS, neurologic complications due to CD19-specific CAR-Ts have also occurred independently of other CRS symptoms. In a recent analysis of CRS in 39 pediatric subjects treated for B-ALL at the Children's Hospital of Philadelphia (CHOP), grade $\geq 3$ CRS was reported in $46 \%$ and encephalopathy was reported in $33 \%$ of patients, with encephalopathy most often occurring later in the course of CRS and after fevers had resolved. ${ }^{71}$ The pathogenesis of the serious neurologic complications seen with certain CAR-T products remains unclear. ${ }^{60,65}$ Severe encephalopathy is unfortunately unresponsive to steroids in most cases and thus predictive models ${ }^{72}$ and alternative treatment strategies are needed.

On-target toxicities. The widespread applicability of CAR-T therapy and its extension beyond B-cell malignancies has in large part been limited by the paucity of known antigens that are truly specific to tumor cells. Expression of target antigens on normal tissues can lead to severe toxicity in the setting of CAR-T therapy, as evidenced by early experience in trials among patients with solid tumors. ${ }^{15,73}$ The comparative success of CD19-specific CAR-Ts is largely explained by the tolerability of associated ontarget toxicities. CD19 is an extracellular glycoprotein whose expression is limited to normal B-cells and malignant B-cell clones, and aplasia of normal B-cells resulting from successful treatment with CD19specific CAR-Ts can be effectively managed with the use of intravenous immunoglobulin infusions. Similarly, in a trial of CAR-Ts targeting the $\kappa$-light chain of human immunoglobulins, on-target toxicities led to the elimination of normal $\kappa$-expressing (but not $\lambda$-expressing) B-cells. ${ }^{74}$ Given the rapidly expanding field of CAR-T therapies, and ongoing clinical trials evaluating novel antigenic targets for both hematologic malignancies and solid tumors, ${ }^{75}$ ontarget toxicities will continue to be a major concern. As discussed below, there has consequently been significant interest in the incorporation of various safety mechanisms into CAR designs with the goal of mitigating any observed toxicities.

Safety strategies. Given the potential for lifethreatening, and often unpredictable toxicities associated with CAR-T therapy, a compelling strategy to improve the safety of such therapy has been the addition of "elimination" or "suicide" genes into CAR constructs.

The herpes simplex virus thymidine kinase (HSV-tk) was the first such transgene to be evaluated in the context of cellular therapy. ${ }^{76}$ HSV-tk-expressing lymphocytes can be killed by administration of the prodrug, ganciclovir, leading to accumulation of toxic metabolites and disruption of DNA synthesis in dividing cells. While this approach has been evaluated clinically in the context of $\mathrm{HSCT},{ }^{77}$ disadvantages include the slow onset of action (due to effects only on diving cells), transgene immunogenicity limiting the in vivo persistence of HSV-tk-expressing cells, ${ }^{78}$ and the potential interference with alternative clinical use of ganciclovir.

One more promising approach has been the inclusion of an inducible caspase-9 (iC9) safety switch, which is based on a modified human caspase- 9 gene fused to the human FK506 binding protein. When incorporated into a CAR, dimerization of $\mathrm{iC} 9$, and subsequent apoptosis of the expressing cells, can be induced by a chemical inducer of dimerization known as AP1903/Rimiducid (Bellicum Pharmaceuticals). In a humanized mouse model, our group recently demonstrated the 
ability of AP1903 to eliminate iC9-containing CD19specific CAR-Ts in a dose-dependent manner, thus allowing the selective containment of CAR-T expansion when clinically appropriate (eg, mild CRS) or the complete deletion of the CAR-Ts to allow B-cell reconstitution. ${ }^{79}$ The iC9 system has been evaluated clinically in the setting of allogeneic HSCT. ${ }^{80}$ There are currently several registered clinical trials evaluating the iC9 gene in the context of CAR-T therapy for solid tu-mors ${ }^{81-83}$ and hematologic malignancies, ${ }^{84-86}$ including a trial of an iC9-containing CD19-directed CAR for the treatment of relapsed/refractory acute lymphoblastic leukemia that our group will be opening at the University of North Carolina. ${ }^{86}$

Another strategy to improve the safety of CAR-Ts has been the incorporation of a truncated form of the epidermal growth factor receptor (EGFRt), with the goal of allowing CAR-Ts to be eliminated in case of toxicity via administration of the anti-EGFR monoclonal antibody, cetuximab. ${ }^{87}$ The EGFRt domain was included in a recent CD19-directed CAR-T product evaluated in clinical trials at the FHCRC/Seattle Children's Hospital $;{ }^{53,55}$ however, the administration of cetuximab was not reported despite the occurrence of 2 treatment-related deaths due to severe CRS and irreversible neurologic toxicity, respectively. ${ }^{55}$

\section{CLINICAL TRIALS OF CAR T-CELLS FOR B-CELL MALIGNANCIES}

Early clinical trial experience. Although initial clinical trials of CAR-Ts focused on patients with solid tumors ${ }^{17}$ the most impressive clinical results to date have occurred in the treatment of B-cell malignancies. As noted above, this is in large part due the ideal candidacy of CD19 as a target for CAR-Ts. The initial experience with CAR-Ts in B-cell malignancies came from a trial conducted in 2008 by investigators at the City of Hope and FHCRC in which a first-generation CD20-specific CAR was evaluated in 7 patients with relapsed or refractory follicular lymphoma (FL) ${ }^{18}$ Although efficacy was limited (1 patient achieved a partial response $[\mathrm{PR}]$ and no patient developed any significant B-cell aplasia), there were also no grade $\geq 3$ adverse events reported and CAR-Ts persisted up to 59 weeks in 4 of 7 patients. The potential toxicity of CAR-Ts was highlighted early, however, by a report from the Memorial Sloan Kettering Cancer Center (MSKCC) describing the death, due to symptoms consistent with CRS, of a patient with chronic lymphocytic leukemia (CLL) who was treated with cyclophosphamide followed by infusion of CD19CD28- $\zeta$ second-generation CAR-Ts. ${ }^{88}$ In 2010, Jensen et al. reported their experience in treating 2 patients with DLBCL with first-generation CD20-specific CAR-Ts and 2 patients with refractory FL with CD19-specific CAR-Ts. As with most trials of firstgeneration CAR-Ts, in vivo persistence was poor (1-7 days). Although this may be at least partially explained by antitransgene immune responses observed in 2 patients, it is unknown whether this activity was directed at the CAR or an included hygromycin resistance gene. ${ }^{19}$ In 2010, Kochenderfer et al. at the NCI published an early report of success in which a patient with FL was treated with a CD19-

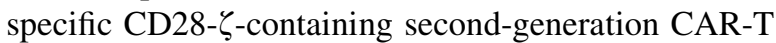
product following lymphodepleting chemotherapy with cyclophosphamide and fludarabine. The authors demonstrated CAR-T persistence until 27 weeks following initial infusion, which was associated with a PR of the patient's lymphoma and, most notably, the development of isolated B-cell aplasia (used as a surrogate marker for CD19 CAR-T persistence and cytotoxic activity) lasting until 39 weeks. ${ }^{36}$ It was not until 2011, however, that the enormous potential of CAR-T therapy was initially demonstrated by the preliminary results of a landmark trial from the University of Pennsylvania (UPenn). ${ }^{89,90}$ In this trial, patients with advanced chemotherapy-resistant CLL were treated, following lymphodepleting chemotherapy, with T-cells lentivirally transduced with a second-generation 4-1BB- $\zeta$-containing $\mathrm{CAR}^{89,90}$ The authors demonstrated significant $(>1000$ fold) in vivo CAR-T expansion, B-cell aplasia, and tumor lysis syndrome, and reported that 2 of the initial 3 patients achieved a CR lasting $>10$ months. Mature trial results published in 2015 showed an overall response rate (ORR) of $57 \%$, with 4 of 14 patients achieving a CR that was negative for MRD, and a median progression-free survival of 7 months. ${ }^{62}$ Although the earliest successes were reported in NHL and CLL, the most impressive results with CAR-T therapy to date have been seen with second-generation CD19-specific CAR-Ts for relapsed and refractory B-ALL for both children and adults, initially demonstrated in trials at $\mathrm{CHOP}^{91,92}$ and the University of Pennsylvania. ${ }^{63,92}$ Significant efficacy has also been demonstrated in DLBCL and indolent B-cell lymphomas. ${ }^{93}$

Clinical trials of CD19-specific CAR T-cells. Clinical trials of CD19-specific CAR-Ts are summarized in detail in Tables I and II. Outcomes have been reported for over 350 patients with B-ALL and over 200 patients with NHL/CLL. There is significant heterogeneity between these trials, including differences in the CAR design, T-cell subsets, lymphodepletion regimens, autologous vs allogeneic T-cells, and the dose of 
Table I. CAR-T clinical trials with reported efficacy data: B-ALL

\begin{tabular}{|c|c|c|c|c|c|c|c|c|c|}
\hline Year & $\begin{array}{l}\text { Academic } \\
\text { institution } \\
\text { (Industry) }\end{array}$ & Antigen & $\begin{array}{l}\text { Treated } \\
\text { population }\end{array}$ & $\begin{array}{l}\text { scFv/Costim. } \\
\text { Domain }\end{array}$ & Vector & Lymphodepletion & $\begin{array}{l}\text { CAR-T dose } \\
\text { range }\end{array}$ & $\begin{array}{l}\text { CRS/Neurologic } \\
\text { toxicity }\end{array}$ & Outcomes \\
\hline 2013 & $\mathrm{BCM}^{33}$ & $\begin{array}{l}\text { CD19+ } \\
\text { virus- } \\
\text { specific }\end{array}$ & $\begin{array}{l}\text { Adult } \\
\qquad \begin{array}{l}\text { B-ALL, } \\
n=4\end{array}\end{array}$ & FMC63/CD28 & $\mathrm{RV}$ & $\begin{array}{l}\text { None, history of } \\
\text { allo-HSCT } \\
\text { 3mo-12 } \\
\text { mo before } \\
\text { infusion }\end{array}$ & $\begin{array}{l}3.8 \times 10^{7}-9.7 \times \\
10^{7} / \mathrm{kg} \\
\text { (allogeneic) }\end{array}$ & $\begin{array}{l}\text { No } G r \geq 3 \text { toxicities } \\
\text { reported }\end{array}$ & $\begin{array}{l}\text { ORR: } 3 / 4 \text {; CR: } 1 / 4 \\
\text { (3 mo); Continued } \\
\text { CR: } 2 / 4(2+ \\
\text { to } 8+\text { mo) }\end{array}$ \\
\hline 2015 & $\begin{array}{c}\mathrm{CHOP}^{92,94-96} \\
\text { (Novartis) }\end{array}$ & CD19 & $\begin{array}{l}\text { Pediatric } \\
\text { B-ALL, } \\
n=60\end{array}$ & FMC63/4-1BB & LV & IC & $\begin{array}{c}1.1 \times 10^{6}-1.7 \times \\
10^{7} / \mathrm{kg}\end{array}$ & $\begin{array}{l}\text { Any Gr CRS: 52/59; } \\
\text { sCRS: } 16 / 59 ; \\
\text { Neurotoxicity NR } \\
\text { (Any Gr neurotoxicity } \\
\text { in 13/30 pts in initial } \\
\text { combined analysis of } \\
\text { pediatric/adult trials) }\end{array}$ & $\begin{array}{l}\text { CR: } 56 / 60 \text {, } \\
\text { MRD(-) in 51/56; } \\
12 \text { mo RFS: } 60 \% ; \\
24 \text { mo RFS: } 53 \% ; \\
12 \text { mo OS: } 79 \% ; \\
24 \text { mo OS: } 61 \%\end{array}$ \\
\hline 2015 & $\begin{array}{l}\text { CPLAGH, } \\
\text { Beijing, } \\
\text { China }^{57}\end{array}$ & CD19 & $\begin{array}{l}\text { Adult } \\
\qquad \begin{array}{l}\text { B-ALL, } \\
n=9\end{array}\end{array}$ & FMC63/4-1BB & LV & $\begin{array}{c}\text { None }(n=7 / 9) \\
\text { Cy-MOAD } \\
(n=2 / 9)\end{array}$ & $\begin{array}{c}3 \times 10^{6}-1 \times \\
10^{7} / \mathrm{kg}\end{array}$ & $\begin{array}{l}\text { Any Gr CRS: } 4 / 9 ; \\
\text { Gr } \geq 3 \text { CRS:3/9 }\end{array}$ & $\begin{array}{l}\text { ORR: 4/9; CR: } 2 / 9 \\
\text { (9 wks, 38+wks), } \\
\text { MRD(-) in } 2 / 2 ; \\
\text { PR: } 2 / 9 ; 18 w k \\
\text { OS: } 5 / 9\end{array}$ \\
\hline 2016 & $\begin{array}{l}\text { CHOP/Global } \\
\text { Multicenter } \\
\text { (Novartis) }\end{array}$ & CD19 & $\begin{array}{l}\text { Pediatric } \\
\text { B-ALL, } \\
\mathrm{n}=34\end{array}$ & FMC63/4-1BB & LV & $\begin{array}{l}\text { IC (FluCy } \\
\text { in majority) }\end{array}$ & $\begin{array}{l}0.2 \times 10^{6}-4 \times \\
10^{6} / \mathrm{kg}(\text { median } \\
\left.2.9 \times 10^{6}\right)\end{array}$ & $\begin{array}{l}\text { Any Gr CRS: 28/34; } \\
\text { Gr } 3 \text { CRS: 7/34; Gr } \\
4 \text { CRS: 8/34; Gr 3-4 } \\
\text { neurotoxicity: } 7 / 34\end{array}$ & $\begin{array}{l}\text { CR/CRi: } 24 / 29, \\
\text { MRD(-) in } 24 / 24 ; \\
6 \text { mo OS: } 89 \% ; \\
6 \text { mo RFS: } 60 \%\end{array}$ \\
\hline 2016 & $\begin{array}{l}\text { CHOP/US } \\
\text { Multicenter } \\
\text { (Novartis) }\end{array}$ & CD19 & $\begin{array}{r}\text { Pediatric } \\
\text { B-ALL, } \\
n=29\end{array}$ & FMC63/4-1BB & LV & FluCy & $\begin{array}{l}2.0-5.0 \times 10^{6} / \mathrm{kg} \\
(\leq 50 \mathrm{~kg}) ; \\
1.0-2.5 \times 10^{8} \\
(>50 \mathrm{~kg})\end{array}$ & $\begin{array}{l}\text { Gr 3-4 CRS: } 11 / 29 ; \\
\text { Gr } 3 \text { neurotoxicity: } \\
\text { 1; Gr 4-5 } \\
\text { neurotoxicity: } 0\end{array}$ & $\begin{array}{l}\text { CR/CRi: } 20 / 29 \\
\text { MRD(-) in } 18 / 20 ; \\
6 \text { mo RFS: } 66.4 \% ; \\
6 \text { mo OS: } 75.7 \%\end{array}$ \\
\hline 2016 & $\begin{array}{r}\mathrm{CHOP}^{99,100} \\
\text { (Novartis) }\end{array}$ & CD19 & $\begin{array}{l}\text { Pediatric } \\
\text { B-ALL, } \\
\mathrm{n}=30^{100} \\
(11 / 30 \\
\text { prior } \\
\text { murine } \\
\text { CAR-Ts) }\end{array}$ & $\begin{array}{c}\text { HuCART19/4-1BB } \\
\text { (humanized) }\end{array}$ & LV & FluCy & Not reported & $\begin{array}{l}\text { Gr } 3 \text { CRS: 3/30; } \\
\text { Gr } 4 \text { CRS: 1/30; } \\
\text { Any Gr } \\
\text { encephalopathy: } \\
\text { 5; Any Gr seizure: } 4\end{array}$ & $\begin{array}{l}\text { CR: } 26 / 30 \text { (7/11 } \\
\text { with prior murine } \\
\text { CAR-T therapy), } \\
\text { MRD(-) in 19/19 } \\
\text { without prior CAR-T } \\
\text { therapy, 5/7 with } \\
\text { prior CAR-T therapy }\end{array}$ \\
\hline 2016 & $\begin{array}{l}\mathrm{FHCRC}^{54,55,58} \\
\text { (Juno) }\end{array}$ & CD19 & $\begin{array}{l}\text { Adult } r / r \\
\text { B-ALL, } \\
n=30\end{array}$ & $\begin{array}{l}\text { FMC63/4-1BB } \\
\text { (EGFRt) }\end{array}$ & LV & $\begin{array}{l}\text { Cy }(n=13 / 30) \\
\quad \text { FluCy } \\
\quad(n=17 / 30)\end{array}$ & $\begin{array}{l}2 \times 10^{5}-2 \times \\
10^{7} / \mathrm{kg} ; \\
\text { defined 1:1 } \\
\text { CD4 }^{+}: \mathbf{C D 8}^{+} \\
\text {ratio }\end{array}$ & $\begin{array}{l}\text { CRS: 25/30; sCRS: } \\
\text { 7/30; one pt died } \\
\text { due to CRS; Gr 3-4 } \\
\text { neurotoxicity: } 14 / 30 ; \\
\text { Gr } \mathbf{5} \text { neurotoxicity: } \\
\mathbf{1 / 3 0}(\mathrm{Gr} \geq 3 \\
\text { neurotoxicity in } \\
\text { 6/6 who received } \\
\text { CAR-Ts dose } \\
\left.\geq 2 \times 10^{6} / \mathrm{kg}\right)\end{array}$ & $\begin{array}{l}\text { CR: 28/30 (17/17 } \\
\text { FluCy, 11/13 Cy), } \\
\text { MRD(-) in 16/17 } \\
\text { FluCy, 10/11 Cy; } \\
\text { Alive in CR: 12/17 } \\
\text { FluCy (median f/u } \\
\text { 300 d), 1/13 Cy } \\
\text { (f/u } 600+\text { d) }\end{array}$ \\
\hline
\end{tabular}




\begin{tabular}{|c|c|c|c|c|c|c|c|c|c|}
\hline 2016 & $\begin{array}{l}\text { GIMI/Multicenter, } \\
\text { China }^{101}\end{array}$ & CD19 & $\begin{array}{l}\text { B-ALL, } \\
\mathrm{n}=102 \text { (47 } \\
\text { adult, } 55 \\
\text { pediatric) }\end{array}$ & $\begin{array}{c}\text { CD19scFv/CD28- } \\
\text { 4-1BB-CD27 } \\
\text { (iCasp9) }\end{array}$ & LV & $\begin{array}{l}\text { FluCy }(n=54), \text { Cy } \\
\qquad \begin{array}{l}(n=17), \text { other } \\
(n=29), \text { none } \\
(n=2)\end{array}\end{array}$ & $\begin{array}{c}1.05 \times 10^{6} / \mathrm{kg} \\
\text { (average) }\end{array}$ & $\begin{array}{c}\text { Gr 0-1 CRS: 73/102; Gr } \\
\text { 3-4 CRS: 3/17 (BM } \\
\text { blasts > 80\%), 8/38 } \\
\text { (BM blasts } \geq 50 \%) ; \\
\text { Neurotoxicity NR. }\end{array}$ & $\begin{array}{l}\text { CR: } 91.3 \%(<50 \% \text { BM } \\
\text { blasts, } \mathrm{n}=69) \\
75.8 \% \text { ( } \geq 50 \% \text { BM } \\
\text { blasts, } \mathrm{n}=33 \text { ); } \\
\text { median OS: } 485 \mathrm{~d} \\
\text { (<50\% BM blasts), } \\
317 \mathrm{~d} \text { ( } \geq 50 \% \text { BM } \\
\text { blasts) }\end{array}$ \\
\hline 2016 & $\begin{array}{l}\text { HYLDH, } \\
\text { Langfang, } \\
\text { China }^{102}\end{array}$ & CD19 & $\begin{array}{l}\text { B-ALL, } \\
\quad n=47 \\
\text { (ages 2-68) }\end{array}$ & CD19scFv/4-1BB & LV & $\begin{array}{l}\text { FluCy }(\mathrm{n}=46 \text {; Flu } \\
\quad 30 \mathrm{mg} / \mathrm{m}^{2} \times 3 \text {, Cy } \\
\left.250 \mathrm{mg} / \mathrm{m}^{2} \times 3\right)\end{array}$ & $\begin{array}{c}5 \times 10^{3}-1.4 \times \\
10^{6} / \mathrm{kg}(\text { median } \\
\left.1.0 \times 10^{5} / \mathrm{kg}\right)\end{array}$ & $\begin{array}{l}\text { Median CRS grade } 2 \\
\text { (range 1-5); Gr } \geq \\
3 \mathrm{CRS} \text { and } \mathrm{Gr} 5 \\
\text { CRS NR; } \\
\text { neurotoxicity NR. }\end{array}$ & $\begin{array}{l}\text { CR/CRi: } 31 / 35, \\
\text { MRD }(-) \text { in } 29 / 35 \\
\text { (15 remained in } \\
\text { CR with median } \mathrm{f} / \mathrm{u} \\
197 \text { d) }\end{array}$ \\
\hline 2016 & $\begin{array}{l}\text { MDACC }^{35} \\
\text { (Ziopharm/ } \\
\text { Intrexon) }\end{array}$ & CD19 & $\begin{array}{l}\text { Adult } \\
\text { B-ALL } \\
\text { undergoing } \\
\text { allo-HSCT, } \\
\mathrm{n}=17\end{array}$ & FMC63/CD28 & SB & $\begin{array}{l}\text { IC (following } \\
\text { allo-HSCT) }\end{array}$ & $\begin{array}{c}1 \times 10^{6}-1 \times \\
10^{8} / \mathrm{m}^{2}\end{array}$ & $\begin{array}{l}\text { No CRS or } \\
\text { neurotoxicity } \\
\text { reported; Acute } \\
\text { GVHD: } 3 / 17\end{array}$ & $\begin{array}{l}\text { Continued CR: } 9 / 17 \\
\text { (median duration } \\
6 \text { mo at last } \\
\text { follow-up); Died in } \\
\text { CR: } 1 / 17\end{array}$ \\
\hline 2016 & $\begin{array}{l}\text { MSKCC }^{63,103-106} \\
\quad \text { (Juno) }\end{array}$ & CD19 & $\begin{array}{l}\text { Adult } r / r \\
\text { B-ALL, } \\
\mathrm{n}=51^{103} \\
\text { (20/51 with } \\
\text { baseline } \\
\text { MRD) }\end{array}$ & SJ25C1/CD28 & $\mathrm{RV}$ & Cy or FluCy & $\begin{array}{c}1 \times 10^{6}-3 \times \\
10^{6} / \mathrm{kg}\end{array}$ & $\begin{array}{l}\text { sCRS: } 14 / 51 \text { (13/31 } \\
\text { baseline morphologic } \\
\text { dz, 1/20 baseline MRD); } \\
\text { Gr } 3-4 \text { neurotoxicity: } \\
\text { 15/51 ( } 11 / 31 \text { baseline } \\
\text { morphologic dz, 4/20 } \\
\text { baseline MRD); Note: } \\
\text { development of this } \\
\text { CAR-T product was } \\
\text { discontinued after } 5 \\
\text { deaths due to } \\
\text { cerebral edema in a } \\
\text { multicenter phase II } \\
\text { trial. }{ }^{69,70,107}\end{array}$ & $\begin{array}{l}\text { CR: 41/50 (CR in } \\
\text { 23/30 with baseline } \\
\text { morphologic dz, } \\
\text { 18/20 with baseline } \\
\text { MRD), MRD(-) in } \\
\text { 33/39 CRs (no MRD } \\
\text { testing in } 2 \text { pts); } \\
\text { 15/33 with } \\
\text { MRD(-) CR } \\
\text { relapsed, 9/33 } \\
\text { MRD(-) CR dz free } \\
\text { 12+ mo; } 6 \text { mo OS: } \\
\text { 73\% (baseline } \\
\text { MRD), 57\% } \\
\text { (baseline } \\
\text { morphologic dz), } \\
\text { 92\% (pts attaining } \\
\text { MRD(-) CR) }\end{array}$ \\
\hline 2016 & $\begin{array}{l}\text { Multicenter } \\
\quad \text { (Kite) }\end{array}$ & CD19 & $\begin{array}{l}\text { B-ALL, } \\
\quad \mathrm{n}=5 \text { (3 } \\
\text { adult, } 2 \\
\text { pediatric) }\end{array}$ & FMC63/CD28 & $\mathrm{RV}$ & $\begin{array}{l}\text { FluCy (Flu } \\
\begin{array}{l}25 \mathrm{mg} / \mathrm{m}^{2} \\
\times 3, \mathrm{Cy} \\
\left.900 \mathrm{mg} / \mathrm{m}^{2}\right)\end{array}\end{array}$ & $\begin{array}{c}1 \times 10^{6} \text { vs } 2 \times \\
10^{6} / \mathrm{kg} \text { (target) }\end{array}$ & $\begin{array}{l}\text { Any Gr CRS: } 5 / 5 ; \text { No } \\
\text { Gr } \geq 3 \text { CRS; Gr } \geq 3 \\
\text { neurotoxicity: } 3 / 5 \text { (3/3 } \\
\text { adult pts); tocilizumab } \\
\text { +/- corticosteroids } \\
\text { +/- siltuximab }(5 / 5)\end{array}$ & $\begin{array}{l}\text { CR: } 5 / 5, M R D(-) \\
\text { in } 5 / 5 \text { (duration } \\
\text { NR) }\end{array}$ \\
\hline
\end{tabular}


Table I. (Continued)

\begin{tabular}{|c|c|c|c|c|c|c|c|c|c|}
\hline Year & $\begin{array}{l}\text { Academic } \\
\text { institution } \\
\text { (Industry) }\end{array}$ & Antigen & $\begin{array}{l}\text { Treated } \\
\text { population }\end{array}$ & $\begin{array}{l}\text { scFv/Costim. } \\
\text { Domain }\end{array}$ & Vector & Lymphodepletion & $\begin{array}{l}\text { CAR-T dose } \\
\text { range }\end{array}$ & $\begin{array}{l}\text { CRS/Neurologic } \\
\text { toxicity }\end{array}$ & Outcomes \\
\hline 2016 & $\mathrm{NCl}^{34}$ & CD19 & $\begin{array}{l}\text { Adult } \\
\text { B-ALL } \\
\text { relapsed } \\
\text { after } \\
\text { allo-HSCT, } \\
\mathrm{n}=5\end{array}$ & FMC63/CD28 & RV & None & $\begin{array}{l}4.2 \times 10^{6}-7.0 \times \\
10^{6} / \mathrm{kg} \\
\text { allogeneic }\end{array}$ & $\begin{array}{l}\text { Gr 3-4 sinus tachycardia: } \\
\text { 3/5; Gr 3-4 } \\
\text { hypotension: } \\
\text { 4/5; Neurotoxicity NR }\end{array}$ & $\begin{array}{l}\text { CR: } 4 / 5 ; M R D(-) \\
\quad \text { in } 4 / 4\end{array}$ \\
\hline 2016 & $\mathrm{NCl}^{59,91}$ & CD19 & $\begin{array}{l}\text { Pediatric } r / r \\
\text { B-ALL, } \\
n=51\end{array}$ & FMC63/CD28 & RV & $\begin{array}{l}\text { FluCy (low-dose } \\
\qquad \begin{array}{l}n=36, \text { high-dose } \\
n=8), \text { FLAG } \\
(n=6), \text { ifos/etop } \\
(n=2)\end{array}\end{array}$ & $\begin{array}{c}1 \times 10^{6}-3 \times \\
10^{6} / \mathrm{kg}\end{array}$ & $\begin{array}{l}\text { Gr } 3-4 \text { CRS: } 7 / 51 ; \text { Gr } \\
\text { 1-2 seizures: 2/51; } \\
\text { Gr } 3 \text { neurotoxicity: } \\
\text { 3/51 }\end{array}$ & 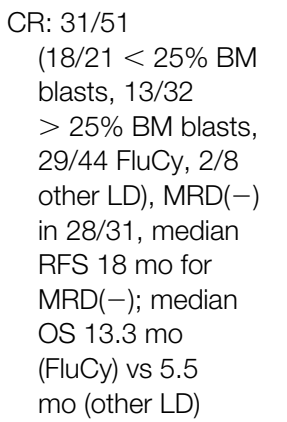 \\
\hline 2016 & $\begin{array}{l}\mathrm{NCl}^{109} \\
\quad \text { (Juno) }\end{array}$ & CD22 & $\begin{array}{l}\text { Pediatric } \\
\text { B-ALL, } \\
\mathrm{n}=9 \text { (7/9 } \\
\text { with prior } \\
\text { CD19 CAR } \\
\text { therapy) }\end{array}$ & m971/4-1BB & LV & $\begin{array}{l}\text { FluCy (Flu } 25 \\
\quad \mathrm{mg} / \mathrm{m}^{2} \times 3 \text {, Cy } \\
\left.900 \mathrm{mg} / \mathrm{m}^{2} \times 1\right)\end{array}$ & $\begin{array}{l}3 \times 10^{5} \mathrm{vs} \\
1 \times 10^{6} / \mathrm{kg}\end{array}$ & $\begin{array}{l}\text { Gr 1-2 CRS: 6/9; } \\
\text { Neurotoxicity NR }\end{array}$ & $\begin{array}{l}\text { CR: } 4 / 9, \mathrm{MRD}(-) \text { in } \\
4 / 4 ; 3 / 3 \text { pts treated } \\
\text { at higher dose are in } \\
\text { sustained remission } \\
\text { at } 3 \text { mo }\end{array}$ \\
\hline 2016 & $\begin{array}{l}\text { Seattle } \\
\text { Children's }{ }^{53} \\
\text { (Juno) }\end{array}$ & CD19 & $\begin{array}{l}\text { Pediatric } \\
\text { B-ALL, } \\
n=43\end{array}$ & $\begin{array}{l}\text { FMC63/4-1BB } \\
\text { (EGFRt) }\end{array}$ & LV & $\begin{array}{l}\text { Cy }(n=27), \text { FluCy } \\
(n=14), \text { CE } \\
(n=1), \\
\text { Flu }(n=1)\end{array}$ & $\begin{array}{l}5 \times 10^{5}-4 \times \\
10^{6} / \mathrm{kg} \\
\text { defined 1:1 } \\
\text { CD4 }^{+}: \mathbf{C D 8}^{+} \\
\text {ratio }\end{array}$ & $\begin{array}{l}\text { CRS: 40/43; sCRS: } \\
\text { 10/43 (severity } \\
\text { correlated to dose } \\
\text { level, but not dz } \\
\text { burden; no toxic } \\
\text { deaths); Any Gr } \\
\text { neurotoxicity: } 21 / 43 ; \\
\text { Severe neurotoxicity: } \\
\text { 10/43 }\end{array}$ & $\begin{array}{l}\text { CR: 40/43, MRD(-) } \\
\text { in 40/40; } 12 \text { mo } \\
\text { OS: 69.5\%; Median } \\
\text { CAR-T persistence: } \\
6.4 \text { mo (>15\% } \\
\text { CD19 }{ }^{+} \text {BM cells), } \\
1.7 \text { mo (<15\% } \\
\text { CD19 }{ }^{+} \text {BM cells); } \\
\text { Loss of CAR-T } \\
\text { persistence } \\
\text { associated with } \\
\text { CD19 }{ }^{+} \text {relapse, } \\
\text { HR } 34\end{array}$ \\
\hline
\end{tabular}




\begin{tabular}{|c|c|c|c|c|c|c|c|c|c|}
\hline 2016 & $\begin{array}{l}\text { UPenn }{ }^{68,92} \\
\text { (Novartis) }\end{array}$ & CD19 & $\begin{array}{l}\text { Adult } r / r \\
\text { B-ALL, } \\
n=30\end{array}$ & FMC63/4-1BB & LV & IC (Cy-based) & $\begin{array}{r}5 \times 10^{7} \mathrm{vs} \\
5 \times 10^{8}\end{array}$ & $\begin{array}{c}\text { Gr } \geq 3 \text { CRS: 22/30; } \\
\text { Gr } 5 \text { CRS: } \mathbf{3 / 3 0} \\
\text { (each received } \\
5 \times 10^{8} \\
\text { CAR-Ts } \\
\text { in single infusion, } \\
\text { each received } \\
\text { tocilizumab + } \\
\text { corticosteroids); } \\
\text { Gr } \geq 3 \\
\text { neurotoxicity: } \\
\text { 1/30 (Gr } 3 \\
\text { encephalopathy) }\end{array}$ & $\begin{array}{l}\text { CR: 15/27; } \\
\text { PR: 1/27 }\end{array}$ \\
\hline 2017 & $\begin{array}{l}\text { University } \\
\text { College } \\
\text { London } \\
\text { (Cellectis) }\end{array}$ & CD19 & $\begin{array}{l}\text { Pediatric } \\
\quad \text { B-ALL, } n=2\end{array}$ & 4g7/4-1BB & LV & $\begin{array}{l}\text { Flu, Cy, } \\
\text { Alemtuzumab } \\
\text { (anti-CD52) }\end{array}$ & $\begin{array}{l}\text { 4.0-4.6 } \\
\times 10^{6} / \mathrm{kg} \\
\text { "universal" } \\
\text { (allogeneic, } \\
\text { TCR }^{-} / \text {CD52 } \\
\text { via TALEN } \\
\text { gene-editing) }\end{array}$ & $\begin{array}{l}\text { No CRS or } \\
\text { neurotoxicity } \\
\text { reported; Gr } \\
2 \text { skin GVHD } \\
\text { in } 1 / 2 \text {. }\end{array}$ & $\begin{array}{l}\text { CR: } 2 / 2 \\
\text { (duration } 12+ \\
\text { and } 18+\text { mo), } \\
\text { both MRD }(-)\end{array}$ \\
\hline
\end{tabular}

Abbreviations: ALL, acute lymphoblastic lymphoma; allo-HSCT, allogeneic hematopoietic stem cell transplantation; auto-HSCT, autologous hematopoietic stem cell transplant; BCM, Baylor College of Medicine; CAR-T, chimeric antigen receptor T-cell; CE, cyclophosphamide + etoposide; costim., costimulatory; CPLAGH, Chinese PLA General Hospital; CHOP, Children's Hospital of Philadelphia; $C R$, complete response or complete remission; CRi, complete remission with incomplete count recovery; Cy, cyclophosphamide; $d z$, disease; etop, etoposoide; FLAG, fludarabine + cytarabine + granulocyte colony-stimulating factor; Flu, fludarabine; FluCy, fludarabine + cyclophosphamide; f/u, follow-up; GIMI, Shenzhen Genoimmune Medical Institute (Shenzhen, China): Gr, grade: HYLDH, Hebei Yanda Lu Daopei Hospital: IC, investigator's choice; ifos, ifosfamide: LV. lentivirus: MDACC, MD Anderson Cancer Center: mo, months; MSKCC, Memorial Sloan Kettering Cancer Center; $M R D$, minimal residual disease; $M R D(-)$, negative evaluation for minimal residual disease; $N C I$, National Cancer Institute; $N E$, not evaluable; $N R$, not reported; ORR, overall response rate (PR or better); OS, overall survival; $P R$, partial response; $p t$, patient; $r / r$, relapsed and/or refractory; $R F S$, relapse-free survival; $R V$, retrovirus; $S B$, Sleeping Beauty; SCFV, single-chain variable fragment; SCRS, severe CRS (requiring ICU management, treatment with tocilizumab and/or corticosteroids); TALEN, transcription activator-like effector nuclease; UPenn, University of Pennsylvania.

Allogeneic CAR-Ts are derived from patient's donor for prior allo-HSCT (except University College London study). Year refers to year most recent results were reported. 
Table II. CAR-T clinical trials with reported efficacy data: B-cell NHL and CLL

\begin{tabular}{|c|c|c|c|c|c|c|c|c|c|}
\hline Year & $\begin{array}{l}\text { Academic } \\
\text { institution } \\
\text { (Industry) }\end{array}$ & Antigen & Treated Population & $\begin{array}{l}\text { scFv/Costim. } \\
\text { Domain }\end{array}$ & Vector & Lympho-depletion & $\begin{array}{l}\text { CAR-T dose } \\
\text { range }\end{array}$ & $\begin{array}{l}\text { CRS/Neurologic } \\
\text { toxicity }\end{array}$ & Outcomes \\
\hline 2012 & $\mathrm{NCl}^{110}$ & CD19 & $\begin{array}{l}\text { Adults: B-NHL or } \\
\text { CLL, } n=8 \\
\text { (4 CLL, } 3 \text { FL, } 1 \\
\text { SMZL) }\end{array}$ & FMC63/CD28 & $\mathrm{RV}$ & $\begin{array}{l}\text { FluCy (Flu } \\
25 \mathrm{mg} / \mathrm{m}^{2} \times \\
5, \text { Cy } 60 \mathrm{mg} / \\
\mathrm{kg} \times 2)\end{array}$ & $\begin{array}{l}3.0 \times 10^{6}- \\
\quad 3.0 \times 10^{7} / \mathrm{kg}\end{array}$ & 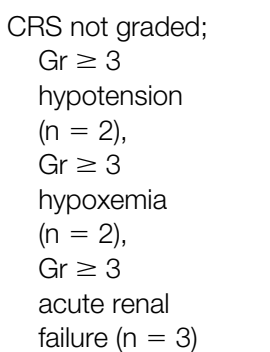 & $\begin{array}{l}\text { ORR: 6/7 } \\
\quad \text { (1/8 NE); CR: } \\
\text { 1/7 (CLL, } \\
\text { 15+ mo); } \\
\text { PR: 5/7 (CLL, } \\
\text { n=2; } \\
\text { FL, n = 2; sMZL, } \\
\text { n=1) }\end{array}$ \\
\hline 2013 & $\mathrm{BCM}^{33}$ & $\begin{array}{l}\text { CD19 + } \\
\quad \text { virus-specific }\end{array}$ & $\begin{array}{l}\text { Adults: relapsed } \\
\text { CLL after allo- } \\
\text { HSCT, } n=4\end{array}$ & FMC63/CD28 & $\mathrm{RV}$ & None & $\begin{array}{l}6.8 \times 10^{7}- \\
1.13 \times 10^{8} / \mathrm{kg} \\
\text { (allogeneic) }\end{array}$ & $\begin{array}{l}\text { No } \mathrm{Gr} \geq 3 \\
\text { toxicities } \\
\text { reported }\end{array}$ & $\begin{array}{l}\text { ORR: } 1 / 4 \text {; PR: } 1 / 4 \\
\quad \text { (duration } 8 \text { wk); } \\
\text { SD: } 1 / 4 \text { (duration } \\
\text { 15+ mo) }\end{array}$ \\
\hline 2013 & $\mathrm{NCl}^{36}$ & CD19 & $\begin{array}{l}\text { Adults: persistent } \\
\text { B-NHL or CLL } \\
\text { after allo-HSCT, } \\
\text { n=15 (4 CLL, } 2 \\
\text { DLBCL, } 4 \mathrm{MCL})\end{array}$ & FMC63/CD28 & $\mathrm{RV}$ & None & $\begin{array}{l}4.0 \times 10^{5}- \\
7.8 \times 10^{6} / \mathrm{kg} \\
\quad(\text { allogeneic) }\end{array}$ & $\begin{array}{l}\mathrm{Gr} \geq 3 \\
\quad \text { fever: } 2 / 15 ; \\
\mathrm{Gr} \geq 3 \\
\text { hypotension: } \\
2 / 15 ; \mathrm{Gr} \geq 3 \\
\text { hypoxia: } 1 / 15\end{array}$ & $\begin{array}{l}\text { ORR: 2/10; CR: } 1 / 10 \\
\text { (CLL, duration } \\
\text { 9+ mo); PR: } 1 \\
\text { (MCL, duration } \\
\text { 3+ mo) }\end{array}$ \\
\hline 2015 & MSKCC $^{111}$ & CD19 & $\begin{array}{r}\text { Adults: poor-risk } \\
\text { aggressive } r / r \\
\text { B-NHL, } n=8\end{array}$ & SJ25C1/CD28 & RV & $\begin{array}{l}\text { Following } \\
\text { HDT-ASCT } \\
\text { with BEAM } \\
\text { conditioning }\end{array}$ & $\begin{array}{l}5 \times 10^{6} / \mathrm{kg} \\
(\mathrm{n}=7) \text { vs } 1 \times \\
10^{7} / \mathrm{kg}(\mathrm{n}=1)\end{array}$ & $\begin{array}{l}\text { CRS: 4/8; } \\
\text { SCRS: 1/8; } \\
\text { Tocilizumab: } \\
\text { 4/8 }\end{array}$ & $\begin{array}{l}\text { ORR: 5/8; CR: 5/8 } \\
\text { (duration } 10+\text { to } \\
18+\text { mo) }\end{array}$ \\
\hline 2015 & $\mathrm{NCl}^{93}$ (Kite) & CD19 & $\begin{array}{l}\text { Adults: B-NHL or } \\
\text { CLL, } \mathrm{n}=15 \text { (4 } \\
\text { CLL, } 9 \\
\text { chemo-refractory } \\
\text { DLBCL, } 2 \text { indolent } \\
\text { B-NHL) }\end{array}$ & FMC63/CD28 & $\mathrm{RV}$ & $\begin{array}{l}\text { FluCy }(\text { Flu } \\
25 \mathrm{mg} / \mathrm{m}^{2} \times \\
5, \text { Cy } 60 \mathrm{vs} \\
120 \mathrm{mg} / \mathrm{kg} \times 1)\end{array}$ & $\begin{array}{l}1.0 \times 10^{6}- \\
5.0 \times 10^{6} / \mathrm{kg}\end{array}$ & $\begin{array}{l}\text { CRS not graded; } \\
\text { Gr } \geq 3 \\
\text { hypotension: } \\
\text { 4/15, Gr } \geq 3 \\
\text { hypoxia: } 2 / 15, \\
\text { Gr } \geq 3 \text { neurologic } \\
\text { toxicity: } 6 / 15 ; \\
\text { Tocilizumab: } 2 / 15\end{array}$ & $\begin{array}{l}\text { ORR: 11/13 (2 NE); } \\
\text { CR: 4/7 DLBCL } \\
\text { (duration } 6 \text { to } \\
22+\text { mo), } 3 / 4 \text { CLL } \\
\text { (duration } 14 \text { to } \\
23+\text { mo), } 1 / 2 \\
\text { indolent B-NHL } \\
\text { (duration } 11+\text { mo) }\end{array}$ \\
\hline
\end{tabular}




\begin{tabular}{|c|c|c|c|c|c|c|c|c|c|}
\hline 2015 & UPenn ${ }^{62}$ & CD19 & $\begin{array}{c}\text { Adults: } r / r \text { CLL, } \\
n=14\end{array}$ & FMC63/4-1BB & LV & $\begin{array}{l}\text { IC (Bend, } \mathrm{n}=6 \\
\quad \text { FluCy, } \mathrm{n}=3 \\
\text { PenCy, } \mathrm{n}=5)\end{array}$ & $\begin{array}{l}1.4 \times 10^{7}-1.1 \\
\times 10^{9} \\
(\text { flat dose })\end{array}$ & $\begin{array}{l}\text { Any Gr CRS } \\
\left.\text { (UPenn }{ }^{62}\right): 9 / 14 ; \\
\text { Gr } 3 \text { CRS: 2/14; } \\
\text { Gr } 4 \text { CRS: 4/14; } \\
\text { Gr } \geq 3 \\
\text { neurotoxicity } \\
\text { (Gr } 4 \text { confusion) } \\
\text { in 1/14, } \\
\text { concurrent } \\
\text { with CRS; } \\
\text { Tocilizumab: 4; } \\
\text { Corticosteroids: } 2\end{array}$ & $\begin{array}{l}\text { ORR: 8/14; CR: 4/ } \\
\text { 14, MRD(-) in 4/4; } \\
\text { PR: 4/14; Median } \\
\text { PFS: } 7 \text { mo; } \\
\text { Median OS: } \\
29 \text { mo; } 18 \text { mo OS: } \\
\text { 71\% }\end{array}$ \\
\hline 2016 & $\mathrm{BCM}^{29}$ & CD19 & $\begin{array}{l}\text { Adults: } r / r \\
\text { DLBCL, } \\
n=6\end{array}$ & $\begin{array}{l}\text { FMC63/CD28 + } \\
\text { FMC63/CD28- } \\
\text { 4-1BB }\end{array}$ & $\mathrm{RV}$ & $\begin{array}{l}\text { FluCy }(\mathrm{Flu} \\
30 \mathrm{mg} / \mathrm{m}^{2} \times 5 \text {, } \\
\text { Cy } 500 \\
\left.\mathrm{mg} / \mathrm{m}^{2} \times 3\right)\end{array}$ & $\begin{array}{l}1-20 \times 10^{6} / \mathrm{m}^{2} \\
\text { (both } 2 \text { nd and } \\
\text { 3rd gen CAR-Ts } \\
\text { simultaneously) }\end{array}$ & $\begin{array}{l}\text { Gr } 2 \text { CRS: 2/6; No } \\
\text { neurotoxicity } \\
\text { reported }\end{array}$ & $\begin{array}{l}\text { ORR: 4/5; CR: 2/5 (1 } \\
\text { NE), longest } \\
\text { 9+ mo; continued } \\
\text { CR: 1/5; PR 1/5; } \\
\text { 3rd gen CAR-Ts } \\
\text { had mean 23- } \\
\text { fold (1.1- to 109- } \\
\text { fold) higher } \\
\text { expansion, } \\
\text { longer } \\
\text { persistence }\end{array}$ \\
\hline 2016 & $\mathrm{BCM}^{74}$ & $\begin{array}{c}\kappa \text {-light } \\
\text { chain }\end{array}$ & $\begin{array}{l}\text { Adults: } r / r \\
\text { B-NHL/CLL, } \\
\mathrm{n}=16(7 \\
\mathrm{NHL}, 2 \\
\mathrm{CLL} / \mathrm{SLL}, \\
7 \mathrm{MM})\end{array}$ & CRL-1758/CD28 & RV & $\begin{array}{l}\text { Cy } 12.5 \mathrm{mg} / \mathrm{kg} \\
(1 / 7 \mathrm{NHL}, 4 / \\
7 \mathrm{MM}) ; \text { none } \\
9 / 16\end{array}$ & $\begin{array}{l}1.7 \times 10^{7}- \\
1.9 \times 10^{8} / \mathrm{m}^{2}\end{array}$ & $\begin{array}{l}\text { No CRS or } \\
\text { neurotoxicity } \\
\text { observed. Gr } 3 \\
\text { lymphopenia in } \\
\text { one pt. No other } \\
\text { Gr } \geq 3 \\
\text { treatment-related } \\
\text { toxicity. }\end{array}$ & $\begin{array}{l}\text { ORR: 3/9; CR: 2/9 } \\
\text { (both DLBCL, } \\
\text { one relapsed } \\
\text { after } 6 \text { wks, } \\
\text { other with CR } \\
\text { 32+ mo); } \\
\text { PR: } 1 / 9\end{array}$ \\
\hline 2016 & $\begin{array}{l}\text { CPLAGH, } \\
\text { Beijing, } \\
\text { China }^{112,113}\end{array}$ & CD20 & $\begin{array}{c}\text { Adults: } r / r \\
\text { B-NHL, } \\
n=11\end{array}$ & AY160760.1/4-1BB & LV & IC (none in 4/11) & $\begin{array}{l}4.1 \times 10^{6}- \\
1.5 \times 10^{7} / \mathrm{kg}\end{array}$ & $\begin{array}{l}\text { No CRS or } \\
\text { neurotoxicity } \\
\text { observed. No } \\
\text { Gr } \geq 3 \text { toxicities } \\
\text { observed other } \\
\text { than hypokalemia } \\
(n=1) \text {, herpes } \\
\text { zoster }(n=1)\end{array}$ & $\begin{array}{l}\text { ORR: 9/11; } \\
\text { CR: 6/11 (duration } \\
5 \text { to } 27+\text { mo); } \\
\text { PR: } 3 / 11 \text {; median } \\
\text { PFS: } 6 \text { mo; } \\
\text { pt with longest } \\
\text { CR had 2nd } \\
\text { CAR-T infusion at } \\
16 \text { mo }\end{array}$ \\
\hline
\end{tabular}


Table II. (Continued)

\begin{tabular}{|c|c|c|c|c|c|c|c|c|c|}
\hline Year & $\begin{array}{l}\text { Academic } \\
\text { institution } \\
\text { (Industry) }\end{array}$ & Antigen & Treated Population & $\begin{array}{l}\text { scFv/Costim. } \\
\text { Domain }\end{array}$ & Vector & Lympho-depletion & $\begin{array}{l}\text { CAR-T dose } \\
\text { range }\end{array}$ & $\begin{array}{l}\text { CRS/Neurologic } \\
\text { toxicity }\end{array}$ & Outcomes \\
\hline 2016 & $\begin{array}{l}\text { FHCRC }^{114} \\
\text { (Juno) }\end{array}$ & CD19 & $\begin{array}{l}\text { Adults: } \\
\text { refractory } \\
\text { CLL, } \\
n=18\end{array}$ & $\begin{array}{l}\text { FMC63/4-1BB } \\
\text { (EGFRt) }\end{array}$ & LV & $\begin{array}{l}\text { FluCy } \\
\qquad \begin{array}{l}(n=15), \text { Flu } \\
(n=2), \text { Cy } \\
(n=1)\end{array}\end{array}$ & $\begin{array}{l}2 \times 10^{5}-2 \times \\
10^{7} / \mathrm{kg} ; \\
\text { defined 1:1 } \\
\text { CD4 }^{+}: \text {CD8 }^{+} \\
\text {ratio }\end{array}$ & $\begin{array}{l}\text { Any Gr CRS: } \\
\text { 17/17; Gr 3-4 } \\
\text { CRS: 4/17; Gr } \geq 3 \\
\text { neurotoxicity: } \\
\text { 4/17. Tocilizumab } \\
\text { + corticosteroids: } \\
\text { 3/17 }\end{array}$ & $\begin{array}{l}\text { ORR: } 13 / 17 \text {; } \\
\text { CR 5/17, } \\
\text { MRD(-) in } \\
\text { 4/4 (1 NE), } \\
\text { none relapsed } \\
\text { with median f/u } \\
\text { 8.4 mo; } \\
\text { PR 8/17 }\end{array}$ \\
\hline 2016 & $\begin{array}{l}\mathrm{FHCRC}^{54,115,116} \\
\text { (Juno) }\end{array}$ & CD19 & $\begin{array}{l}\text { Adults: B-NHL, } \\
\mathrm{n}=32(21 \\
\mathrm{DLBCL} \\
5 \mathrm{FL}, 4 \mathrm{MCL})\end{array}$ & $\begin{array}{l}\text { FMC63/4-1BB } \\
\text { (EGFRt) }\end{array}$ & LV & $\begin{array}{l}\text { Cy, CE, or } \\
\text { FluCy }\end{array}$ & $\begin{array}{l}2 \times 10^{5}-2 \times \\
10^{7} / \mathrm{kg} ; \\
\text { defined 1:1 } \\
\text { CD4 }^{+}: \text {CD8 }^{+} \\
\text {ratio }\end{array}$ & $\begin{array}{l}\text { sCRS: } 4 / 32 \text { (all } \\
\text { cases in pts } \\
\text { treated with } \\
\text { FluCy and } \\
\geq 1 \times 10^{6} \\
\text { CAR-Ts/kg); } \\
\text { tocilizumab: } 3 ; \\
\text { Gr } \geq 3 \\
\text { neurotoxicity: } \\
\text { 9/32 (7/9 had } \\
\text { received FluCy, } \\
8 / 9 \text { had received } \\
\geq 1 \times 10^{6} \\
\text { CAR-Ts/kg) }\end{array}$ & $\begin{array}{l}\text { ORR: 19/30; } \\
\text { CR: 10/30 } \\
\text { (8/21 DLBCL, } \\
\text { 2/5 FL, O/4 MCL); } \\
\text { 9/10 CRs in pts } \\
\text { who received } \\
\text { FluCy; } \\
\text { CAR expansion } \\
\text { and } \\
\text { persistence better } \\
\text { with FluCy }\end{array}$ \\
\hline 2016 & $\begin{array}{l}\text { MDACC }^{35} \\
\text { (Ziopharm/ } \\
\text { Intrexon) }\end{array}$ & CD19 & $\begin{array}{l}\text { Adults: undergoing } \\
\text { autologous } \\
(\mathrm{n}=7) \\
\text { or allogeneic } \\
(\mathrm{n}=2) \mathrm{HSCT} \\
\text { for } \mathrm{B}-\mathrm{NHL}(4 \\
\text { DLBCL, } \\
\text { 3 FL, } 1 \mathrm{MCL}) \\
1 \mathrm{nHL}\end{array}$ & FMC63/CD28 & SB & $\begin{array}{c}\text { Following HSCT } \\
\text { (preparative } \\
\text { regimen } / C \text { ) }\end{array}$ & $\begin{array}{l}1 \times 10^{7}-5 \times \\
10^{9} / \mathrm{m}^{2} \\
\text { (autologous } \\
\text { or allogeneic) }\end{array}$ & $\begin{array}{l}\text { No CRS or } \\
\text { neurotoxicity } \\
\text { reported. }\end{array}$ & $\begin{array}{l}\text { Continued CR: } \\
\text { 6/7 autologous } \\
\text { (median duration } \\
26 \text { mo at last } \\
\text { follow-up), 0/2 } \\
\text { allogeneic }\end{array}$ \\
\hline 2016 & MSKCC $^{117}$ & CD19 & $\begin{array}{l}\text { Adults: } r / r \\
\quad \text { CLL, } n=11\end{array}$ & SJ25C1/CD28 & RV & $\begin{array}{l}\text { FluCy }(n=3), \\
\text { Cy }(n=6), \\
\text { Bend }(n=2) ;+ \\
\text { ibrutinib }(n=5)\end{array}$ & $\begin{array}{r}1 \times 10^{7} / \mathrm{kg} \\
\text { (median) }\end{array}$ & $\begin{array}{l}\text { sCRS: 2/11 } \\
\text { (2/5 ibrutinib, } \\
\text { 0/6 non-ibrutinib) }\end{array}$ & $\begin{array}{l}\text { ORR: 5/11 } \\
\text { (4/5 ibrutinib, 1/6 } \\
\text { non-ibrutinib); } \\
\text { CR 2, MRD(-) } \\
\text { in 2/2 (duration } \\
\text { 16+ and } \\
\text { 50+ mo); } \\
\text { continued } \\
\text { CR: } 1 / 11 \text {; } \\
\text { PR: } 2 / 11\end{array}$ \\
\hline
\end{tabular}




\begin{tabular}{|c|c|c|c|c|c|c|c|c|c|}
\hline 2016 & $\begin{array}{l}\text { Multicenter } \\
\text { (Kite) }^{118}\end{array}$ & CD19 & $\begin{array}{l}\text { Adults: B-NHL, } \\
n=6 \\
\text { (3 PMBCL, } 3 \\
\text { transformed FL) }\end{array}$ & FMC63/CD28 & $\mathrm{RV}$ & $\begin{array}{l}\text { FluCy } \\
\qquad \begin{array}{l}\text { (Flu } 30 \mathrm{mg} / \\
\mathrm{m}^{2} \times 3 \\
\text { Cy } 500 \mathrm{mg} / \\
\left.\mathrm{m}^{2} \times 3\right)\end{array}\end{array}$ & $\begin{array}{c}2 \times 10^{6} / \mathrm{kg} \\
\text { (target) }\end{array}$ & $\begin{array}{l}\text { Any Gr CRS: } \\
\text { 6/6; No Gr } \geq 3 \\
\text { CRS; Any Gr } \\
\text { neurotoxicity: 4/6; } \\
\text { Gr 3-4 } \\
\text { neurotoxicity: 2/6 }\end{array}$ & $\begin{array}{l}\text { ORR: 6/6; CR: } \\
\text { 6/6 (median f/u } \\
3.2 \text { mo) }\end{array}$ \\
\hline 2016 & $\begin{array}{l}\text { Multicenter } \\
\text { (Juno) }\end{array}$ & CD19 & $\begin{array}{l}\text { Adults: } r / r \text { B-NHL, } \\
n=14(13 \\
\text { DLBCL, } 1 \mathrm{MCL})\end{array}$ & FMC63/4-1BB & LV & $\begin{array}{l}\text { FluCy (Flu } \\
\qquad \begin{array}{l}30 \mathrm{mg} / \mathrm{m}^{2} \text {, Cy } \\
300 \mathrm{mg} / \mathrm{m}^{2} \text { ) }\end{array}\end{array}$ & $5 \times 10^{7} / \mathrm{kg}$ & $\begin{array}{l}\text { Gr } 1-2 \text { CRS: } \\
3 \text { (grading system } \\
\text { NR) Gr } \geq 3 \text { CRS: } 0 \\
\text { Gr } \geq 3 \\
\text { neurotoxicity: } \\
2 \text { (1 Gr } 4 \\
\text { encephalopathy, } 1 \\
\text { Gr } 4 \text { seizure) }\end{array}$ & $\begin{array}{l}\text { DLBCL }(\mathrm{n}=13, \\
2 \mathrm{NE} \text { - ORR: } \\
\text { 9/11; CR: } 8 / 11 \\
\text { (7/8 remained } \\
\text { in CR, follow-up } \\
\text { duration NR); PR: } \\
\text { 1/11. } \\
\text { MCL - ORR: } 0 / 1\end{array}$ \\
\hline 2016 & $\mathrm{NCl}^{34}$ & CD19 & $\begin{array}{l}\text { Adults: B-NHL } \\
\text { or CLL, relapsed } \\
\text { following allo- } \\
\text { HSCT, } \\
\mathrm{n}=15 \text { (5 CLL, } 5 \\
\text { DLBCL, } 5 \mathrm{MCL})\end{array}$ & FMC63/CD28 & $\mathrm{RV}$ & $\begin{array}{l}\text { Following } \\
\quad \text { allogeneic HCT }\end{array}$ & $\begin{array}{c}4 \times 10^{5}-8.2 \times \\
10^{6} / \mathrm{kg}\end{array}$ & $\begin{array}{l}\text { CRS not graded; } \\
\qquad \mathrm{Gr} \geq 3 \text { fever: } 4 / 15 ; \\
\mathrm{Gr} \geq 3 \\
\text { tachycardia: } \\
\text { 3/15; Gr } \geq 3 \\
\text { hypotension } \\
\text { 3/15; Gr } \geq 3 \\
\text { headache } 1 / 15\end{array}$ & $\begin{array}{l}\text { ORR: 4/15; } \\
\text { CR: } 2 / 15 \text { (1/5 CLL } \\
\text { with } \\
\text { duration } 30+\text { mo, } \\
\text { 1/5 DLBCL with } \\
\text { duration } 6+\text { mo) }\end{array}$ \\
\hline 2016 & $\mathrm{NCl}^{120}$ (Kite) & CD19 & $\begin{array}{l}\text { Adults: } \\
\text { B-NHL, } \mathrm{n}=22 \\
\text { (19 DLBCL, } 2 \\
\text { FL, 1 MCL) }\end{array}$ & FMC63/CD28 & $\mathrm{RV}$ & $\begin{array}{l}\text { FluCy (Flu } 30 \\
\text { mg/m } \mathrm{m}^{2} \times 3 \text {, Cy } \\
300 \mathrm{vs} 500 \\
\left.\mathrm{mg} / \mathrm{m}^{2} \times 3\right)\end{array}$ & $\begin{array}{l}1.0 \times 10^{6}- \\
\quad 6.0 \times 10^{6} / \mathrm{kg}\end{array}$ & $\begin{array}{l}\text { Gr } \geq 3 \\
\quad \text { Neurotoxicity } \\
12 / 22 \text { (confusion, } \\
\text { dysphagia, } \\
\text { encephalopathy, } \\
\text { gait disturbances); } \\
\text { Gr } \geq 3 \\
\text { hypotension 4/22 }\end{array}$ & $\begin{array}{l}\text { ORR: 16/22; } \\
\text { CR: 12/22; } \\
\text { (9/19 DLBCL } \\
\text { with duration } \\
\text { 7-20 mo, } \\
\text { 2/2 FL, 1/1 MCL); } \\
\text { PR: 4/19 DLBCL }\end{array}$ \\
\hline 2016 & $\mathrm{NCl}^{121}$ & CD19 & $\begin{array}{l}\text { Adults: B-NHL, } \\
\mathrm{n}=9 \\
\text { (4 DLBCL, 2 FL, } 1 \\
\text { Burkitt, } 1 \\
\text { unclassified) }\end{array}$ & $\begin{array}{r}\text { HuCAR19/CD28 } \\
\text { (fully human) }\end{array}$ & LV & $\begin{array}{l}\text { FluCy (Flu } 30 \\
\quad \mathrm{mg} / \mathrm{m}^{2} \times 3 \text {, Cy } \\
300 \mathrm{mg} / \mathrm{m}^{2} \times 3 \text { ) }\end{array}$ & $\begin{array}{l}6.6 \times 10^{5}- \\
2.0 \times 10^{6} / \mathrm{kg}\end{array}$ & $\begin{array}{l}\text { Any } \operatorname{Gr} \mathrm{CRS}\left(\mathrm{NCl}^{61}\right) \text { : } \\
\text { 9/8 (1 NE); } \mathrm{Gr} 3-4 \\
\text { CRS: } 3 / 8\end{array}$ & $\begin{array}{l}\text { ORR: 6/8 (1 NE); CR: } \\
\text { 2/7 (duration } \\
\text { 2+ mo) }\end{array}$ \\
\hline 2016 & Upenn $^{122,123}$ & CD19 & $\begin{array}{l}\text { Adults: } r / r \\
\quad \text { CLL, } n=35\end{array}$ & FMC63/4-1BB & LV & IC & $\begin{array}{l}5 \times 10^{7} \text { vs } \\
5 \times 10^{8} \\
(\text { phase I); } \\
5 \times 10^{8} \\
\text { (phase II) }\end{array}$ & $\begin{array}{l}\text { Any Gr CRS } \\
\text { (Upenn'22): } \\
\text { 19/35; Gr 3-4 } \\
\text { CRS: 7/35; } \\
\text { Tocilizumab: 4; } \\
\text { CAR-T dose not } \\
\text { associated with } \\
\text { CRS development } \\
\text { or severity }\end{array}$ & $\begin{array}{l}\text { ORR: } 13 / 30 \\
\text { (4/13 low-dose, } \\
\text { 9/17 high-dose); } \\
\text { CR: } 7 / 30 \text { (1/13 } \\
\text { low-dose, } 6 / 17 \\
\text { high-dose; } \\
\text { duration } \\
5 \text { to } 34+\text { mo); } \\
\text { PR: } 3 / 17\end{array}$ \\
\hline
\end{tabular}


Table II. (Continued)

\begin{tabular}{|c|c|c|c|c|c|c|c|c|c|}
\hline Year & $\begin{array}{l}\text { Academic } \\
\text { institution } \\
\text { (Industry) }\end{array}$ & Antigen & Treated Population & $\begin{array}{l}\text { scFv/Costim. } \\
\text { Domain }\end{array}$ & Vector & Lympho-depletion & $\begin{array}{l}\text { CAR-T dose } \\
\text { range }\end{array}$ & $\begin{array}{l}\text { CRS/Neurologic } \\
\text { toxicity }\end{array}$ & Outcomes \\
\hline 2016 & Upenn $^{124-127}$ & CD19 & $\begin{array}{l}\text { Adults: } r / r \mathrm{NHL} \text {, } \\
\mathrm{n}=27(13 \\
\mathrm{DLBCL}, 125 \\
\left.\mathrm{FL}^{126}\right)\end{array}$ & FMC63/4-1BB & LV & IC & $\begin{array}{l}\text { DLBCL - } \\
3.10 \times \\
10^{6}-6.75 \times \\
10^{6} / \mathrm{kg} . \\
\mathrm{FL}-3.08 \times \\
10^{6}-8.87 \times \\
10^{6} / \mathrm{kg}\end{array}$ & $\begin{array}{l}\text { DLBCL - Any } \\
\text { Gr CRS (Upenn }{ }^{62} \text { ): } \\
\text { 9/13; Gr } \geq 3 \\
\text { CRS: } 1 / 13 ; \text { Gr } \geq 3 \\
\text { Neurotoxicity: 1/ } \\
\text { 13. FL - Any } \\
\text { Gr CRS: } 6 / 14 \\
\text { Gr } \geq 3 \text { CRS: } 2 ; \text { Gr } 5 \\
\text { encephalitis } \\
\text { (possibly } \\
\text { treatment- } \\
\text { related) }\end{array}$ & $\begin{array}{l}\text { DLBCL - ORR: } 7 / 13 \text {; } \\
\text { CR: 6/13, none } \\
\text { relapsed; } \\
\text { Median PFS: } \\
5.8 \text { mo } \\
\text { FL - ORR: } 11 / 14 ; \\
\text { CR 9/14; } 11 \text { mo } \\
\text { PFS: } 77 \%\end{array}$ \\
\hline 2017 & $\begin{array}{l}\text { Multicenter }{ }^{128,129} \\
\text { (Kite) }\end{array}$ & CD19 & $\begin{array}{r}\text { Adults: refractory } \\
\text { DLBCL, } \mathrm{n}=7\end{array}$ & FMC63/CD28 & $\mathrm{RV}$ & $\begin{array}{c}\text { FluCy (Flu } 30 \\
\mathrm{mg} / \mathrm{m}^{2} \text {. Cy } \\
\left.500 \mathrm{mg} / \mathrm{m}^{2}\right)\end{array}$ & $\begin{array}{c}1.1 \times 10^{6}-2.0 \times \\
10^{6} / \mathrm{kg} \text { (target: } \\
\left.2.0 \times 10^{6}\right)\end{array}$ & $\begin{array}{l}\text { Any } \mathrm{Gr} C R S\left(\mathrm{NCl}^{61}\right) \text { : } \\
\text { 6/7; } \mathrm{Gr} \geq 3 \\
\text { CRS: } 1 / 7 ; \mathrm{Gr} \geq 3 \\
\text { neurotoxicity: 4/7; } \\
\text { Gr } 4 \text { CRS, Gr } 4 \\
\text { neurotoxicity, and } \\
\text { Gr } 5 \text { intracranial } \\
\text { hemorrhage in } \\
\text { one pt (death } \\
\text { deemed unrelated } \\
\text { to CAR-Ts); } \\
\text { Tocilizumab: } 6 / 7 ; \\
\text { Corticosteroids: } 4 / 7\end{array}$ & $\begin{array}{l}\text { ORR: 5/7; CR: } \\
\text { 4/7 ( } 3 \text { ongoing } \\
\text { with duration } \\
12+\mathrm{mo} \text { ) }\end{array}$ \\
\hline
\end{tabular}

Abbreviations: allo-HSCT, allogeneic hematopoietic stem cell transplantation; auto-HSCT, autologous hematopoietic stem cell transplant; B-NHL, B-cell non-Hodgkin Iymphoma; BCM, Baylor College of Medicine; BEAM, carmustine, etoposide, cytarabine, and melphalan; Bend, bendamustine; CAR-T, chimeric antigen receptor T-cell; CE, cyclophosphamide + etoposide; Chemo, chemotherapy; costim., costimulatory; CPLAGH, Chinese PLA General Hospital; CHOP, Children's Hospital of Philadelphia; CLL, chronic lymphocytic leukemia; CR, complete response or complete remission; Cy, cyclophosphamide; $D L B C L$, diffuse large B-cell lymphoma; $d z$, disease; FL, follicular lymphoma; Flu, fludarabine; FluCy, fludarabine + cyclophosphamide; f/u, follow-up; gen generation; Gr, grade; HDT-ASCT, high-dose therapy and autologous stem cell transplant; HSCT, hematopoietic stem cell transplantation; IC, investigator's choice; ifos, ifosfamide; $L V$, lentivirus; MCL, mantle cell lymphoma: MDACC, MD Anderson Cancer Center; mo, months: MSKCC, Memorial Sloan Kettering Cancer Center: MRD, minimal residual disease: MRD(-), negative evaluation for minimal residual disease: $N C I$, National Cancer Institute: $N E$, not evaluable: $N R$, not reported: $n H L$, nodular Hodgkin Lymphoma: NHL, non-Hodgkin lymphoma: NR, not reported; ORR, overall response rate (PR or better); OS, overall survival; pen, pentostatin; PMBCL. Primary Mediastinal B-Cell Lymphoma; $P R$, partial response; $p t$, patient; $r / r$, relapsed and/or refractory; RFS, relapse-free survival; $R V$, retrovirus; $S B$, Sleeping Beauty; $S C F V$, single-chain variable fragment; $s C R S$, severe CRS (requiring ICU management, treatment with tocilizumab and/or corticosteroids); $S M Z L$, splenic marginal zone lymphoma; UPenn, University of Pennsylvania.

Allogeneic CAR-Ts are derived from patient's donor for prior allo-HSCT. Year refers to year most recent results were reported. 
CAR-Ts administered. Rates of CR in larger trials have ranged from $50 \%$ to over $90 \%$. Considering all pediatric and adult patients in aggregate who were treated with CD19-specific CAR-Ts in the United States, we estimate the combined rate of CR or continued CR to be close to $80 \%$, with a rate of MRD-negative CR of over $60 \%$. Efficacy for B-NHL and CLL is somewhat lower, with an estimated ORR around 60\% across reported trials.

Toxicity rates have varied significantly across studies, likely reflecting the differences in the various factors described above. The median rate of severe or grade $\geq 3$ CRS is around $25 \%$ based on available data, and has ranged from less than $15 \%{ }^{59}$ to over $70 \%{ }^{68}$ (although differences may be partly explained by varia-tion in grading systems). At least 10 treatment-related deaths have occurred, predominantly among subjects with BALL.

To date, MSKCC, FHCRC, and UPenn have reported on the largest number of adult B-ALL patients treated with CD19-specific CAR-Ts. At the 2016 annual meeting of the American Society of Clinical Oncology (ASCO), investigators from MSKCC presented an update of their experience treating 51 adult patients with relapsed or refractory CD19 ${ }^{+}$B-ALL with secondgeneration CD19-specific CAR-Ts containing the CD28 costimulatory domain. ${ }^{103}$ Sixty-one percent of patients had morphologic disease at the time of T-cell infusion, with the remainder having evidence of MRD. The median age for patients in the morphologic disease cohort was 40 and the median age in the mini-mal disease cohort was 53. Median follow-up was 8.5 months (range 1-54 months) and 17 of 50 evaluable patients had $\geq 1$ year of follow up. Patients with morphologic disease had received a median of 3 previous lines of therapy, whereas those in the minimal disease cohort had received a median of 2 previous lines of therapy. This included prior blinatumomab in 12 of 51 patients and prior allogeneic HSCT in 18 of 51 patients. Of 51 patients, 15 were Philadelphia chromosome positive $(\mathrm{Ph}+)$. The $\mathrm{CR}$ rate was $77 \%$ among patients with baseline morphologic disease and 90\% among patients with baseline minimal disease. Patients attaining CR were found to be MRD-negative in 33 of 39 cases where MRD-assessment was available. Fifteen of 33 patients attaining an MRD-negative CR relapsed, whereas 9 of 33 remained disease free with $>1$ year follow up. Severe CRS was seen in $44 \%$ of patients in the morphologic disease cohort and none of the patients in the minimal disease cohort. Grade 3/4 neurotoxicity occurred in $40 \%$ of patients with morphologic disease versus $14 \%$ of patients with minimal disease. A multicenter phase II trial of this CAR-T product was opened in 2015; however, this trial was recently terminated after
5 patients died due to treatment-related cerebral edema. ${ }^{69,70,107}$ These results have not yet been formally reported and the cause of the increased toxicity on this trial remains unclear.

Investigators from UPenn also presented an update of their trial of a 4-1BB-containing second-generation CD19-specific CAR-T product at the 2016 ASCO annual meeting. ${ }^{68}$ Thirty patients with relapsed or refractory B-ALL, with a median age of approximately 44, were treated in 4-dosing cohorts. At least 9 patients had earlier received blinatumumab and at least 9 patients had undergone earlier allogeneic HSCT. Grade $\geq 3$ CRS was reported in 22/30 patients, including 3 deaths due to severe CRS (each had received the highest dose of CAR-Ts in a single infusion). Of note, grade $\geq 3$ neurotoxicity was only reported in 1 of 30 patients.

The group at the FHCRC published the results of a phase I/II trial of second-generation 4-1BB-containing CD19-specific CAR-Ts in 30 adults (median age 40) with relapsed or refractory B-ALL. ${ }^{55}$ Patients had received a median of 3 previous lines of chemotherapy and 11 of 30 patients had relapsed following allogeneic HSCT. Before CAR-T infusion, patients were treated with a cyclophosphamide-based lymphodepletion regimen with or without the addition of fludarabine. As discussed above, the investigators in this trial selected for $\mathrm{CD}^{+}$and $\mathrm{CD}^{+}$cells, transduced each subset separately, and then treated patients with a defined 1:1 ratio of $\mathrm{CD} 4^{+}: \mathrm{CD} 8^{+} \mathrm{CAR}-\mathrm{Ts}$. Complete remissions were seen in 28 of 30 patients, and 26 of these patients were negative for MRD. The addition of fludarabine was associated with an improvement in both CAR-T persistence and disease-free survival with 12 of 17 such patients reported to be alive and in CR (median follow-up 300 days) compared with 1 of 13 patients who received lymphodepletion with cyclophosphamide alone (follow-up $>600$ days). Severe CRS was reported in 7 of 30 patients and grade $\geq 3$ neurotoxicity occurred in 15 of 30 patients. One patient died due to severe CRS and another due to irreversible neurotoxicity.

For pediatric ALL, the most extensive experience of CD19-specific CAR-T therapy has come out of CHOP, Seattle Children's, and the NCI. At the 2016 ASCO annual meeting, investigators from CHOP presented an update on their largest trial to date of CD19-specific CAR-Ts for pediatric ALL, reporting outcomes for $60 \mathrm{pa}-$ tients aged 1.7 to 24 (median 11) years. Of 60 patients, 39 had already undergone allogeneic HSCT, 44 had detectable disease at baseline, and 16 were in an MRDnegative remission. Severe CRS was reported in approximately $27 \%$ of patients. Of 60 patients, 56 attained a CR and 51 of those patients were found to be MRD negative. The 2-year relapse-free survival and overall survival were $53 \%$ and $61 \%$, respectively. 
At the 2016 American Society of Hematology annual meeting, investigators from the NCI presented the outcomes of 51 pediatric patients with ALL who were treated with a second-generation CD19-specific CAR-T product containing the CD28 endodomain. ${ }^{59}$ Eleven patients had primary refractory ALL, 5 had $\mathrm{Ph}+$ disease, and 6 had CNS disease. Grade 3-4 CRS was seen in 7 of 51 patients and grade 3 neurotoxicity was seen in 3 of 51 patients. Of 51 patients, 31 attained a CR and 28 were found to be negative for MRD. The use of fludarabine/cyclophosphamidebased lymphodepletion in 36 of 51 patients was associated with significantly better outcomes, with a median overall survival of 13.3 months compared with 5.5 months among patients receiving other lymphodepletion regimens.

Also at the 2016 American Society of Hematology annual meeting, investigators from Seattle Children's reported outcomes for 43 pediatric patients with B-ALL who were treated with CD19-specific CAR-Ts. ${ }^{53}$ Similar to the adult-ALL trial at FHCRC discussed above, patients were infused with a defined composition of $\mathrm{CD} 4^{+}: \mathrm{CD} 8^{+} \mathrm{CAR}-\mathrm{Ts}$. Severe CRS and severe neurotoxicity were both reported in 10 of 43 patients, with no reported deaths due to treatment-related toxicity. Of 43 patients, 40 attained a CR and all were MRD negative. The 12-month overall survival was $70 \%$.

Despite the impressive efficacy seen in trials of CD19-specific CAR-Ts to date, the significant rate of CRS and/or neurotoxicity, coupled with our lack of ability to accurately predict and effectively manage such toxicities, underscores the need for further optimization before the wider application of CAR-T therapies. Incorporating safety mechanisms into the CAR will likely prove to be an immediate and important component of this optimization. Alternatively, if proven to be scalable and highly reproducible, methodologies allowing the production of more uniform CAR-T products ${ }^{55}$ and gene-editing techniques that lead to more consistent CAR transgene expression ${ }^{44,46}$ may represent valuable future approaches to better standardize therapeutic potential, while minimizing collateral toxicities.

Beyond CD19-specific CAR T-cells for B-cell malignancies. Although CD19 is highly expressed in B-cell leukemias and NHLs, many patients do not respond to CD19-directed therapy, and in certain patients who do initially respond, CD19-negative relapse has also been described. ${ }^{130}$ Additional targets are under investigation for the treatment of B-cell malignancies, including CD20, CD22, tyrosine kinase-like orphan receptor 1 (ROR1), and the $\kappa$-light chain of human immunoglobulins.
Shah et al. ${ }^{109}$ recently reported preliminary results of a trial conducted at the NCI in which autologous CD22specific CAR-Ts were infused following lymphodepletion with fludarabine and cyclophosphamide in 9 pediatric subjects with B-ALL. Of these patients, 7 had relapsed following previous CD19-specific CAR-Ts and 6 were shown to have CD19 ${ }^{\mathrm{dim} / \text { neg }}$ tumor cells. Treatment-related toxicities included grade 3 diarrhea in 1 patient and grade $\leq 2 \mathrm{CRS}$ in 7 patients. Of 9 patients, 7 obtained an MRD-negative $C R$ and 3 were in a sustained $\mathrm{CR}$ at 3 months.

A clinical trial was previously conducted at BCM evaluating CAR-Ts targeting the $\kappa$-light chain of human immunoglobulins for the treatment of relapsed or refractory $\kappa$-expressing NHL, CLL, or multiple myeloma (MM) ${ }^{74}$ A total of 16 patients were treated, including 7 with NHL, 2 with CLL, and 7 with MM. Patients received either no lymphodepletion or limited lymphodepletion consisting of cyclophosphamide $12.5 \mathrm{mg} / \mathrm{kg}$. There were no grade $\geq 3$ toxicities attributable to the CAR-Ts; however, in patients with MM (who had higher baseline B-cell counts), there was evidence of a decrease in normal circulating $\kappa$-expressing B-cells. Of the patients with NHL/CLL, the ORR was 3 of 9 and 2 patients with DLBCL attained a CR (1 relapsed after 6 weeks and the other remained in CR at a follow-up of 32 months).

Third-generation CD20-specific CAR-Ts including both the CD28 and 4-1BB costimulatory domains have previously been evaluated by Till et al. at the FHCRC. Three patients with B-cell NHL were treated. One patient developed grade 3 hypoxemia potentially related to CAR-Ts. Two patients without evaluable disease at baseline remained progression free for 12 and 24 months and a third patient attained a PR before relapsing 12 months following CAR-T administration. More recently, a second-generation CD20-specific CAR-T product containing the CD28 costimulatory domain was evaluated in a clinical trial at the Chinese PLA General Hospital. Eleven patients with relapsed or refractory B-NHL were treated. No CRS or neurotoxicity were observed. The ORR was 9 of 11 (82\%), with 6 patients achieving $\mathrm{CR}$ and a median progression-free survival of 6 months (see Table II). ${ }^{112,113}$

ROR 1 is another proposed target for the treatment of B-cell malignancies. ROR 1 is principally expressed during embryonic development after which its expression is thought to be negligible in normal tissues. ROR1 is aberrantly expressed by many malignancies, however, ${ }^{131}$ and preclinical studies of ROR1-specific CAR-Ts have shown promise. ${ }^{92}$ Clinical trials are currently open at the FHCRC (for ROR1-positive CLL, ALL, and mantle cell lymphoma) ${ }^{132}$ and at the M.D. Anderson Cancer Center (MDACC; for CLL). ${ }^{133}$ 


\section{NOVEL APPROACHES TO CAR T-CELL DESIGN}

In addition to the evaluation of novel targets for CAR-Ts, many innovative approaches are being developed to both improve antitumor activity and to reduce toxicities. Examples include the development of CARs engineered to secrete proinflammatory cytokines to protect them from inhibitory signals in the tumor microenvironment, the inclusion of a cytokine-receptor in addition to the CAR to provide cytokine-mediated growth stimulation to the engineered T-cells, and the inclusion of natural killer cell receptors in engineered Tcells to allow better discrimination between tumor cells and nonmalignant cells. ${ }^{134,135}$ Although a comprehensive discussion is beyond the scope of this review, several promising strategies are highlighted below.

Improving CAR T-cell specificity via dual antigen recognition. Given the challenges in identifying antigens that are truly specific to a given tumor, there has been significant interest in developing CAR-Ts that would require the recognition of multiple antigens in combination to exploit their full potential, thereby allowing better discrimination between tumor cells and normal tissue. ${ }^{136-139}$ One such approach has been the expression of two CARs on the same cell, each with a distinct $\mathrm{scFv}$, and both with incomplete signaling domains such that simultaneous engagement of the two CARs would be required for optimal T-cell activation. ${ }^{139}$ Another approach has been the development of inhibitory CARs (iCARs) which incorporate the signaling domains of immunoinhibitory receptors (cytotoxic T-lymphocyte-associated protein 4 or programmed cell death protein 1) with the goal of dampening T-cell activation in the presence of an antigen expressed on normal tissues, while allowing full T-cell activation via a separate CAR when the same cell encounters a different, tumor-associated antigen. ${ }^{137}$ Roybal et al. ${ }^{138}$ recently described an innovative combinatorially activated T-cell circuit, which they termed a "Two Antigen AND-Gate Circuit," whereby activation of a synthetic Notch receptor for one antigen induces the expression of a CAR targeted toward a second antigen. Although none of these techniques have yet been evaluated in humans, further development of clinically-feasible techniques to improve CAR-T specificity will likely be an important prerequisite to expanding the applicability of such therapies.

Strategies to prevent antigen escape. Whereas concern for off-target toxicities is driving efforts to improve CAR-T specificity, this has been somewhat less of a concern thus far in the development of CAR-Ts for Bcell malignancies. Perhaps more relevant to B-cell malignancies, is the occurrence of disease relapses due to antigen escape. Despite the successes of CD19directed CAR-Ts for B-ALL, CD19-negative relapse has been reported in several trials. ${ }^{55,59,91,94}$ Several mechanisms have been observed, including the development of mutations in CD19, expression of alternative splice variants of CD19, and complete loss of CD19-expression, which was reported in a trial among 2 patients who developed a relapse due to myeloid lineage switch, both harboring a rearrangement of the mixed lineage leukemia gene. ${ }^{130,140}$ One strategy for B-ALL has been to target alternative surface antigens other than CD19, and as mentioned above, a trial recently investigated the use of CD22-directed CAR-Ts for relapsed pediatric B-ALL. ${ }^{109}$ Although not yet evaluated in clinical trials, there has also been substantial interest in the possibility of targeting two or more antigens simultaneously, which could potentially be accomplished by pooling CAR-T products, expressing multiple CARs in the same cells, or designing CARs that include two scFvs in tandem. ${ }^{140}$

Universal CARs. Technical or economic challenges associated with the production of autologous cellular products may also limit the widespread clinical applicability of CAR-Ts. Inadequate leukapheresis, failure of CAR-T manufacturing, and rapid progression of the disease while CAR-Ts are being generated may all cause severe limitations for the routine use of CARTs. Banked, third-party CAR-Ts have been evaluated in the context of concurrent or prior HSCT, with CAR-Ts derived from the patient's donor lymphocytes; however, many of the same challenges remain with donor-derived CAR-Ts, and such therapies are only potentially applicable to a minority of patients. The heterogeneity of both autologous and donor-derived allogeneic CAR-Ts also presents several challenges, including unpredictable efficacy and toxicity. In an attempt to develop "universal" CAR-Ts that could be produced in a standardized fashion from T-cells derived from one or more healthy unmatched donors, with subsequent administration to multiple patients, several groups have developed geneediting techniques such as prokaryotic type II CRISPR-Cas9, transcription activator-like effector nucleases, and zinc-finger nucleases to eliminate endogenous $\alpha \beta$-TCR expression in T-cells to remove the risk of inducing graft-versus-host disease. ${ }^{141-144}$ Investigators at the University College of London demonstrated the possibility of using transcription activator-like effector nuclease gene-editing techniques to produce T-cells deficient in expression of both the endogenous $\alpha \beta$-TCR and CD52 (for the purposes of inducing recipient immunosuppression by 
using the anti-CD52 monoclonal antibody, alemtuzumab), with subsequent lentiviral transduction to express a CD19-specific CAR. ${ }^{141}$ Initial clinical assessment of this "off the shelf" CAR-T product in 2 infants with relapsed/refractory $\mathrm{CD} 9^{+}$B-ALL produced ongoing molecular remission in both patients (see Table I) ${ }^{37,38}$ and larger clinical trials are underway to further validate this approach. ${ }^{145,146}$

\section{CONCLUSIONS}

The field of cancer immunotherapy has seen remarkable advances over the past decade, leading to long-term remissions in diseases that would otherwise be rapidly fatal. The theoretical benefit of redirecting the immune system to target cancer cells has long been appreciated, but it was not until the development of immune checkpoint inhibitors that this potential became a reality for large numbers of patients. As is clear from the clinical trials discussed above, CAR-Ts have given us the ability to further unleash the power of cell-mediated immunity against cancer cells, now in a highly-targeted manner that has not previously been possible. This has led to unprecedented successes in the treatment of B-ALL and other B-cell malignancies, and we remain hopeful that similar successes will soon be replicated in other hematologic malignancies and in solid tumors. Combination with other immunotherapeutics is also likely to further maximize the potential of CAR-Ts. ${ }^{147}$ While the power of CAR-Ts is clear, it is also clear that we require a better understanding of how these artificially created receptors interact with the complex signaling networks of the immune system. Further elucidation of the biology of CAR-Ts and their downstream effects will allow us to minimize unpredictable toxicities and improve their therapeutic potential.

\section{ACKNOWLEDGMENTS}

Conflicts of Interest: All authors have read the journal's policy on disclosure of potential conflicts of interest and have none to declare. The manuscript has been reviewed and approved by all named authors. This work was supported in part by a grant from the University Cancer Research Fund (UCRF, grant no: 2015-T2-08).

\section{REFERENCES}

1. Sun C, Dotti G, Savoldo B. Utilizing cell-based therapeutics to overcome immune evasion in hematologic malignancies. Blood 2016;127:3350-9.

2. Schreiber RD, Old LJ, Smyth MJ. Cancer immunoediting: integrating immunity's roles in cancer suppression and promotion. Science 2011;331:1565-70.

3. Gaillard H, Garcia-Muse T, Aguilera A. Replication stress and cancer. Nat Rev Cancer 2015;15:276-89.
4. Billingham RE, Brent L, Medawar PB. Quantitative studies on tissue transplantation immunity. II. The origin, strength and duration of actively and adoptively acquired immunity. Proc R Soc Lond B Biol Sci 1954;143:58-80.

5. Gross G, Waks T, Eshhar Z. Expression of immunoglobulin-T-cell receptor chimeric molecules as functional receptors with antibodytype specificity. Proc Natl Acad Sci U S A 1989;86:10024-8.

6. Kuwana Y, Asakura Y, Utsunomiya N, et al. Expression of chimeric receptor composed of immunoglobulin-derived $\mathrm{V}$ regions and T-cell receptor-derived C regions. Biochem Biophys Res Commun 1987;149:960-8.

7. Gill S, Maus MV, Porter DL. Chimeric antigen receptor T cell therapy: 25years in the making. Blood Rev 2016;30:157-67.

8. Chen L, Ashe S, Brady WA, et al. Costimulation of antitumor immunity by the B7 counterreceptor for the T lymphocyte molecules CD28 and CTLA-4. Cell 1992;71:1093-102.

9. Chen L, Flies DB. Molecular mechanisms of $\mathrm{T}$ cell costimulation and co-inhibition. Nat Rev Immunol 2013;13: 227-42.

10. Gimmi CD, Freeman GJ, Gribben JG, Gray G, Nadler LM. Human T-cell clonal anergy is induced by antigen presentation in the absence of B7 costimulation. Proc Natl Acad Sci U S A 1993;90:6586-90.

11. Eshhar Z, Waks T, Gross G, Schindler DG. Specific activation and targeting of cytotoxic lymphocytes through chimeric single chains consisting of antibody-binding domains and the gamma or zeta subunits of the immunoglobulin and T-cell receptors. Proc Natl Acad Sci U S A 1993;90:720-4.

12. Deeks SG, Wagner B, Anton PA, et al. A phase II randomized study of HIV-specific T-cell gene therapy in subjects with undetectable plasma viremia on combination antiretroviral therapy. Mol Ther 2002;5:788-97.

13. Pule MA, Savoldo B, Myers GD, et al. Virus-specific T cells engineered to coexpress tumor-specific receptors: persistence and antitumor activity in individuals with neuroblastoma. Nat Med 2008; 14:1264-70.

14. Louis CU, Savoldo B, Dotti G, et al. Antitumor activity and longterm fate of chimeric antigen receptor-positive $\mathrm{T}$ cells in patients with neuroblastoma. Blood 2011;118:6050-6.

15. Lamers CH, Sleijfer S, van Steenbergen S, et al. Treatment of metastatic renal cell carcinoma with CAIX CAR-engineered T cells: clinical evaluation and management of on-target toxicity. Mol Ther 2013;21:904-12.

16. Park JR, Digiusto DL, Slovak M, et al. Adoptive transfer of chimeric antigen receptor re-directed cytolytic $\mathrm{T}$ lymphocyte clones in patients with neuroblastoma. Mol Ther 2007;15:825-33.

17. Kershaw MH, Westwood JA, Parker LL, et al. A phase I study on adoptive immunotherapy using gene-modified $\mathrm{T}$ cells for ovarian cancer. Clin Cancer Res 2006;12:6106-15.

18. Till BG, Jensen MC, Wang J, et al. Adoptive immunotherapy for indolent non-Hodgkin lymphoma and mantle cell lymphoma using genetically modified autologous CD20-specific T cells Blood 2008;112:2261-71.

19. Jensen MC, Popplewell L, Cooper LJ, et al. Antitransgene rejection responses contribute to attenuated persistence of adoptively transferred CD20/CD19-specific chimeric antigen receptor redirected $\mathrm{T}$ cells in humans. Biol Blood Marrow Transplant 2010;16:1245-56.

20. Dotti G, Gottschalk S, Savoldo B, Brenner MK. Design and development of therapies using chimeric antigen receptorexpressing T cells. Immunol Rev 2014;257:107-26.

21. Hacein-Bey-Abina S, Garrigue A, Wang GP, et al. Insertional oncogenesis in 4 patients after retrovirus-mediated gene therapy of SCID-X1. J Clin Invest 2008;118:3132-42. 
22. von Kalle C, Deichmann A, Schmidt M. Vector integration and tumorigenesis. Hum Gene Ther 2014;25:475-81.

23. Scholler J, Brady TL, Binder-Scholl G, et al. Decade-long safety and function of retroviral-modified chimeric antigen receptor $\mathrm{T}$ cells. Sci Transl Med 2012;4:132ra153.

24. Finney HM, Lawson AD, Bebbington CR, Weir AN. Chimeric receptors providing both primary and costimulatory signaling in T cells from a single gene product. J Immunol 1998;161: 2791-7.

25. Savoldo B, Ramos CA, Liu E, et al. CD28 costimulation improves expansion and persistence of chimeric antigen receptormodified T cells in lymphoma patients. J Clin Invest 2011;121: 1822-6.

26. Imai C, Mihara K, Andreansky M, et al. Chimeric receptors with 4-1BB signaling capacity provoke potent cytotoxicity against acute lymphoblastic leukemia. Leukemia 2004;18:676-84.

27. Carpenito C, Milone MC, Hassan R, et al. Control of large, established tumor xenografts with genetically retargeted human T cells containing CD28 and CD137 domains. Proc Natl Acad Sci U S A 2009;106:3360-5.

28. Zhong XS, Matsushita M, Plotkin J, Riviere I, Sadelain M. Chimeric antigen receptors combining 4-1BB and CD28 signaling domains augment PI3kinase/AKT/Bcl-XL activation and CD8 + T cell-mediated tumor eradication. Mol Ther 2010; $18: 413-20$.

29. Gomes da Silva D, Mukherjee M, Srinivasan M, et al. Direct comparison of in vivo fate of second and third-generation CD19-specific chimeric antigen receptor (CAR)-T cells in patients with B-Cell lymphoma: Reversal of toxicity from tonic signaling. Blood 2016;128:1851.

30. Geldres C, Savoldo B, Dotti G. Chimeric antigen receptorredirected T cells return to the bench. Semin Immunol 2016; 28:3-9.

31. Sharifzadeh Z, Rahbarizadeh F, Shokrgozar MA, et al. Genetically engineered $\mathrm{T}$ cells bearing chimeric nanoconstructed receptors harboring TAG-72-specific camelid single domain antibodies as targeting agents. Cancer Lett 2013;334:237-44.

32. Zhang AH, Yoon JH, Kim YC, Scott DW. Targeting FVIIIspecific B cells using BAR-transduced regulatory T cells. Blood 2016;128:329.

33. Cruz CR, Micklethwaite KP, Savoldo B, et al. Infusion of donorderived CD19-redirected virus-specific T cells for B-cell malignancies relapsed after allogeneic stem cell transplant: a phase 1 study. Blood 2013;122:2965-73.

34. Brudno JN, Somerville RP, Shi V, et al. Allogeneic T cells that express an anti-CD19 chimeric antigen receptor induce remissions of B-Cell malignancies that progress after allogeneic hematopoietic stem-cell transplantation without causing graftversus-host disease. J Clin Oncol 2016;34:1112-21.

35. Kebriaei P, Singh H, Huls MH, et al. Phase I trials using Sleeping Beauty to generate CD19-specific CAR T cells. J Clin Invest 2016;126:3363-76.

36. Kochenderfer JN, Wilson WH, Janik JE, et al. Eradication of Blineage cells and regression of lymphoma in a patient treated with autologous $\mathrm{T}$ cells genetically engineered to recognize CD19. Blood 2010;116:4099-102.

37. Qasim W, Zhan H, Samarasinghe S, et al. Molecular remission of infant B-ALL after infusion of universal TALEN gene-edited CAR T cells. Sci Transl Med 2017;9.

38. Qasim W, Amrolia PJ, Samarasinghe S, et al. First clinical application of Talen engineered universal CAR19 T cells in B-ALL. Blood 2015; 126:2046.

39. Montini E, Cesana D, Schmidt M, et al. Hematopoietic stem cell gene transfer in a tumor-prone mouse model uncovers low genotoxicity of lentiviral vector integration. Nat Biotechnol 2006;24:687-96.

40. Kebriaei P, Huls H, Jena B, et al. Infusing CD19-directed T cells to augment disease control in patients undergoing autologous hematopoietic stem-cell transplantation for advanced B-lymphoid malignancies. Hum Gene Ther 2012;23:444-50.

41. Manuri PV, Wilson MH, Maiti SN, et al. piggyBac transposon/ transposase system to generate CD19-specific T cells for the treatment of B-lineage malignancies. Hum Gene Ther 2010; 21:427-37.

42. Till BG, Jensen MC, Wang J, et al. CD20-specific adoptive immunotherapy for lymphoma using a chimeric antigen receptor with both CD28 and 4-1BB domains: pilot clinical trial results. Blood 2012;119:3940-50.

43. Ellis J. Silencing and variegation of gammaretrovirus and lentivirus vectors. Hum Gene Ther 2005;16:1241-6.

44. Eyquem J, Mansilla-Soto J, Giavridis T, et al. Targeting a CAR to the TRAC locus with CRISPR/Cas9 enhances tumour rejection. Nature 2017;543:113-7.

45. Schumann K, Lin S, Boyer E, et al. Generation of knock-in primary human T cells using Cas9 ribonucleoproteins. Proc Natl Acad Sci U S A 2015;112:10437-42.

46. MacLeod DT, Antony J, Martin AJ, et al. Integration of a CD19 CAR into the TCR Alpha Chain Locus Streamlines Production of Allogeneic Gene-Edited CAR T Cells. Mol Ther 2017;25: 949-61.

47. Gattinoni L, Lugli E, Ji Y, et al. A human memory T cell subset with stem cell-like properties. Nat Med 2011;17:1290-7.

48. Berger C, Jensen MC, Lansdorp PM, Gough M, Elliott C, Riddell SR. Adoptive transfer of effector CD8 $+\mathrm{T}$ cells derived from central memory cells establishes persistent $\mathrm{T}$ cell memory in primates. J Clin Invest 2008;118:294-305.

49. Hinrichs CS, Borman ZA, Cassard L, et al. Adoptively transferred effector cells derived from naive rather than central memory CD8 $+\mathrm{T}$ cells mediate superior antitumor immunity. Proc Natl Acad Sci U S A 2009;106:17469-74.

50. Gattinoni L, Klebanoff CA, Palmer DC, et al. Acquisition of full effector function in vitro paradoxically impairs the in vivo antitumor efficacy of adoptively transferred CD8 + T cells. J Clin Invest 2005;115:1616-26.

51. Xu Y, Zhang M, Ramos CA, et al. Closely related T-memory stem cells correlate with in vivo expansion of CAR.CD19-T cells and are preserved by IL-7 and IL-15. Blood 2014;123:3750-9.

52. Cieri N, Camisa B, Cocchiarella F, et al. IL-7 and IL-15 instruct the generation of human memory stem $\mathrm{T}$ cells from naive precursors. Blood 2013;121:573-84.

53. Gardner R, Finney O, Smithers H, et al. CD19CAR T cell products of defined CD4:CD8 composition and transgene expression show prolonged persistence and durable MRD-negative remission in pediatric and young adult B-Cell all. Blood 2016;128: 219.

54. Turtle CJ, Hanafi LA, Berger C, et al. Rate of durable complete response in ALL, NHL, and CLL after immunotherapy with optimized lymphodepletion and defined composition CD19 CAR-T cells. J Clin Oncol 2016;34 (suppl; abstr 102).

55. Turtle CJ, Hanafi LA, Berger C, et al. CD19 CAR-T cells of defined CD4+:CD8 + composition in adult B cell ALL patients. J Clin Invest 2016;126:2123-38.

56. Dudley ME, Yang JC, Sherry R, et al. Adoptive cell therapy for patients with metastatic melanoma: evaluation of intensive myeloablative chemoradiation preparative regimens. J Clin Oncol 2008;26:5233-9.

57. Dai H, Zhang W, Li X, et al. Tolerance and efficacy of autologous or donor-derived $\mathrm{T}$ cells expressing CD19 chimeric antigen 
receptors in adult B-ALL with extramedullary leukemia. Oncoimmunology 2015;4:e1027469.

58. Turtle CJ, Hanafi LA, Berger C, et al. Addition of fludarabine to cyclophosphamide lymphodepletion improves in vivo expansion of CD19 chimeric antigen receptor-modified T cells and clinical outcome in adults with B cell acute lymphoblastic leukemia. Blood 2015;126:3773.

59. Lee DW, Stetler-Stevenson M, Yuan CM, et al. Long-term outcomes following CD19 CAR T cell therapy for B-ALL are superior in patients receiving a fludarabine/cyclophosphamide preparative regimen and post-CAR hematopoietic stem cell transplantation. Blood 2016;128:218.

60. Brudno JN, Kochenderfer JN. Toxicities of chimeric antigen receptor T cells: recognition and management. Blood 2016;127: 3321-30.

61. Lee DW, Gardner R, Porter DL, et al. Current concepts in the diagnosis and management of cytokine release syndrome. Blood 2014; 124:188-95.

62. Porter DL, Hwang WT, Frey NV, et al. Chimeric antigen receptor $\mathrm{T}$ cells persist and induce sustained remissions in relapsed refractory chronic lymphocytic leukemia. Sci Transl Med 2015; 7:303ra139.

63. Davila ML, Riviere I, Wang X, et al. Efficacy and toxicity management of 19-28z CAR T cell therapy in B cell acute lymphoblastic leukemia. Sci Transl Med 2014;6:224ra225.

64. Common Terminology Criteria for Adverse Events (CTCAE) Version 4.03. US Department of Health and Human Services, Bethesda, MD, 2010.

65. Bedoya F, Frigault MJ, Maus MV. The flipside of the power of engineered T cells: observed and potential toxicities of genetically modified T cells as therapy. Mol Ther 2017;25:314-20.

66. Kenderian SS, Ruella M, Shestova O, et al. Ruxolitinib prevents cytokine release syndrome after CART cell therapy without impairing the anti-tumor effect in a xenograft model. Blood 2016; 128:652.

67. Ruella M, Kenderian SS, Shestova O, et al. Kinase inhibitor ibrutinib prevents cytokine-release syndrome after anti-CD19 chimeric antigen receptor T cells (CART) for B cell neoplasms. Blood 2016;128:2159.

68. Frey N, Shaw PA, Hexner EO, et al. Optimizing chimeric antigen receptor (CAR) T cell therapy for adult patients with relapsed or refractory ( $\mathrm{r} / \mathrm{r}$ ) acute lymphoblastic leukemia (ALL). J Clin Oncol 2016;34 (suppl; abstr 7002).

69. Juno Therapeutics, Inc. Study Evaluating the Efficacy and Safety of JCAR015 in Adult B-cell Acute Lymphoblastic Leukemia (BALL) (ROCKET). In: ClinicalTrials.gov [Internet]. Bethesda (MD): National Library of Medicine (US). Available at: https://clinicaltrials.gov/ct2/show/NCT02535364; 2000. Accessed March 17, 2017. NLM Identifier: NCT02535364.

70. Juno Therapeutics Inc. Juno Therapeutics Reports Fourth Quarter and 2016 Financial Results. Available at: http://ir. junotherapeutics.com/phoenix.zhtml? $\mathrm{c}=253828 \& \mathrm{p}=$ irol-news Article \&ID $=2250772 ; 2017$. Accessed March 6, 2017.

71. Fitzgerald JC, Weiss SL, Maude SL, et al. Cytokine release syndrome after chimeric antigen receptor $\mathrm{T}$ cell therapy for acute lymphoblastic leukemia. Crit Care Med 2017;45:e124-31.

72. Teachey DT, Lacey SF, Shaw PA, et al. Identification of predictive biomarkers for cytokine release syndrome after chimeric antigen receptor T-cell therapy for acute lymphoblastic leukemia. Cancer Discov 2016;6:664-79.

73. Morgan RA, Yang JC, Kitano M, Dudley ME, Laurencot CM, Rosenberg SA. Case report of a serious adverse event following the administration of $\mathrm{T}$ cells transduced with a chimeric antigen receptor recognizing ERBB2. Mol Ther 2010;18:843-51.
74. Ramos CA, Savoldo B, Torrano V, et al. Clinical responses with $\mathrm{T}$ lymphocytes targeting malignancy-associated kappa light chains. J Clin Invest 2016;126:2588-96.

75. Holzinger A, Barden M, Abken H. The growing world of CAR T cell trials: a systematic review. Cancer Immunol Immunother 2016;65:1433-50.

76. Bonini C, Ferrari G, Verzeletti S, et al. HSV-TK gene transfer into donor lymphocytes for control of allogeneic graft-versusleukemia. Science 1997;276:1719-24.

77. Ciceri F, Bonini C, Stanghellini MT, et al. Infusion of suicidegene-engineered donor lymphocytes after family haploidentical haemopoietic stem-cell transplantation for leukaemia (the TK007 trial): a non-randomised phase I-II study. Lancet Oncol 2009; 10:489-500.

78. Berger C, Flowers ME, Warren EH, Riddell SR. Analysis of transgene-specific immune responses that limit the in vivo persistence of adoptively transferred HSV-TK-modified donor T cells after allogeneic hematopoietic cell transplantation. Blood 2006; 107:2294-302.

79. Diaconu I, Ballard B, Zhang M, et al. Inducible Caspase-9 selectively modulates the toxicities of CD19-specific chimeric antigen receptor-modified T cells. Mol Ther 2017;25:580-92.

80. Di Stasi A, Tey SK, Dotti G, et al. Inducible apoptosis as a safety switch for adoptive cell therapy. N Engl J Med 2011;365: 1673-83.

81. Baylor College of Medicine. 3rd Generation GD-2 Chimeric Antigen Receptor and iCaspase Suicide Safety Switch, Neuroblastoma, GRAIN (GRAIN). In: ClinicalTrials.gov [Internet]. Bethesda (MD): National Library of Medicine (US). Available at: https://clinicaltrials.gov/ct2/show/NCT01822652; 2000. Accessed March 7, 2017. NLM Identifier: NCT01822652.

82. National Cancer Institute (NCI). A Phase I Trial of T Cells Expressing an Anti-GD2 Chimeric Antigen Receptor in Children and Young Adults With GD2+ Solid Tumors. In: ClinicalTrials.gov [Internet]. Bethesda (MD): National Library of Medicine (US). Available at: https://clinicaltrials.gov/ct2/show/ NCT02107963; 2000. Accessed March 17, 2017. NLM Identifier: NCT02107963.

83. Memorial Sloan Kettering Cancer Center. Malignant Pleural Disease Treated With Autologous T Cells Genetically Engineered to Target the Cancer-Cell Surface Antigen Mesothelin. In: ClinicalTrials.gov [Internet]. Bethesda (MD): National Library of Medicine (US). Available at: https://clinicaltrials.gov/ ct2/show/NCT02414269; 2000. Accessed March 17, 2017. NLM Identifier: NCT02414269.

84. Peking University. Evaluation of 4th Generation Safetydesigned CAR T Cells Targeting High-risk and Refractory B Cell Lymphomas (4SCAR19273). In: ClinicalTrials.gov [Internet]. Bethesda (MD): National Library of Medicine (US). Available at: https://clinicaltrials.gov/ct2/show/NCT 02247609; 2000. Accessed March 7, 2017. NLM Identifier: NCT02247609.

85. Shenzhen Geno-Immune Medical Institute. A Phase I/II Multiple Center Trial of 4SCAR19 Cells in the Treatment of Relapsed and Refractory B Cell Malignancies. In: ClinicalTrials.gov [Internet]. Bethesda (MD): National Library of Medicine (US). Available at: https://clinicaltrials.gov/ct2/show/NCT0 3050190; 2000. Accessed March 7, 2017. NLM Identifier: NCT03050190.

86. UNC Lineberger Comprehensive Cancer Center. Administration of Autologous CAR-T CD19 Antigen With Inducible Safety Switch in Patients With Relapsed/Refractory Acute Lymphoblastic Leukemia. In: ClinicalTrials.gov [Internet]. Bethesda (MD): National Library of Medicine (US). Available at: 
https://clinicaltrials.gov/ct2/show/NCT03016377; 2000. Accessed March 7, 2017. NLM Identifier: NCT03016377.

87. Wang X, Chang WC, Wong CW, et al. A transgene-encoded cell surface polypeptide for selection, in vivo tracking, and ablation of engineered cells. Blood 2011;118:1255-63.

88. Brentjens R, Riviere I, Hollyman D, et al. 401. Unexpected toxicity of cyclophosphamide followed by adoptively transferred CD19-targeted T cells in a patient with Bulky CLL. Mol Ther 2009; 17:S157.

89. Porter DL, Levine BL, Kalos M, Bagg A, June CH. Chimeric antigen receptor-modified $\mathrm{T}$ cells in chronic lymphoid leukemia. $\mathrm{N}$ Engl J Med 2011;365:725-33.

90. Kalos M, Levine BL, Porter DL, et al. T cells with chimeric antigen receptors have potent antitumor effects and can establish memory in patients with advanced leukemia. Sci Transl Med 2011;3:95ra73.

91. Lee DW, Kochenderfer JN, Stetler-Stevenson M, et al. T cells expressing CD19 chimeric antigen receptors for acute lymphoblastic leukaemia in children and young adults: a phase 1 dose-escalation trial. Lancet 2015;385:517-28.

92. Maude SL, Frey N, Shaw PA, et al. Chimeric antigen receptor T cells for sustained remissions in leukemia. N Engl J Med 2014; 371:1507-17.

93. Kochenderfer JN, Dudley ME, Kassim SH, et al. Chemotherapyrefractory diffuse large B-cell lymphoma and indolent B-cell malignancies can be effectively treated with autologous $\mathrm{T}$ cells expressing an anti-CD19 chimeric antigen receptor. J Clin Oncol 2015;33:540-9.

94. Maude SL, Teachey DT, Rheingold SR, et al. Sustained remissions with CD19-specific chimeric antigen receptor (CAR)modified $\mathrm{T}$ cells in children with relapsed/refractory ALL. J Clin Oncol 2016;34 (suppl; abstr 3011).

95. Grupp SA, Maude SL, Shaw PA, et al. Durable remissions in children with relapsed/refractory ALL treated with T Cells engineered with a CD19-targeted chimeric antigen receptor (CTL019). Blood 2015;126:681.

96. Grupp SA, Kalos M, Barrett D, et al. Chimeric antigen receptormodified T cells for acute lymphoid leukemia. N Engl J Med 2013;368:1509-18.

97. Grupp SA, Laetsch TW, Buechner J, et al. Analysis of a global registration trial of the efficacy and safety of CTL019 in pediatric and young adults with relapsed/refractory acute lymphoblastic leukemia (all). Blood 2016;128:221.

98. Maude SL, Pulsipher MA, Boyer MW, et al. Efficacy and safety of CTL019 in the first us phase II multicenter trial in pediatric relapsed/refractory acute lymphoblastic leukemia: results of an interim analysis. Blood 2016;128:2801.

99. Maude SL, Barrett DM, Rheingold SR, et al. Efficacy of humanized CD19-targeted chimeric antigen receptor (CAR)-modified T cells in children with relapsed ALL. J Clin Oncol 2016;34 (suppl; abstr 3007).

100. Maude SL, Barrett DM, Rheingold SR, et al. Efficacy of humanized CD19-targeted chimeric antigen receptor (CAR)-modified $\mathrm{T}$ cells in children and young adults with relapsed/refractory acute lymphoblastic leukemia. Blood 2016;128:217.

101. Chang LJ, Dong L, Liu YC, et al. Safety and efficacy evaluation of 4SCAR19 chimeric antigen receptor-modified $\mathrm{T}$ cells targeting B cell acute lymphoblastic leukemia-threeyear follow-up of a multicenter phase I/II study. Blood 2016;128:587.

102. Deng B, Chang AH, Yang J, et al. Safety and efficacy of low dose CD19 targeted chimeric antigen receptor T (CAR-T) cell immunotherapy in 47 cases with relapsed refractory B-cell acute lymphoblastic leukemia (B-ALL). Blood 2016;128:649.
103. Park JH, Riviere I, Wang X, Purdon T, Sadelain M, Brentjens RJ. Impact of disease burden on long-term outcome of 19-28z CAR modified $\mathrm{T}$ cells in adult patients with relapsed B-ALL. J Clin Oncol 2016;34 (suppl; abstr 7003).

104. Park JH, Riviere I, Wang X, et al. Implications of minimal residual disease negative complete remission (MRD-CR) and allogeneic stem cell transplant on safety and clinical outcome of CD19-targeted 19-28z CAR modified T cells in adult patients with relapsed, refractory B-Cell ALL. Blood 2015;126:682.

105. Brentjens RJ, Davila ML, Riviere I, et al. CD19-targeted T cells rapidly induce molecular remissions in adults with chemotherapy-refractory acute lymphoblastic leukemia. Sci Transl Med 2013;5:177ra138.

106. Brentjens RJ, Riviere I, Park JH, et al. Safety and persistence of adoptively transferred autologous CD19-targeted T cells in patients with relapsed or chemotherapy refractory B-cell leukemias. Blood 2011;118:4817-28.

107. Dyer O. FDA lifts hold on cancer immunotherapy trial placed after patients died. BMJ 2016;354.

108. Shah B, Huynh V, Sender LS, et al. High rates of minimal residual disease-negative $(\mathrm{MRD}-$ ) complete responses $(\mathrm{CR})$ in adult and pediatric and patients with relapsed/refractory acute lymphoblastic leukemia (R/R all) treated with KTE-C19 (AntiCD19 chimeric antigen receptor [CAR] T cells): preliminary results of the ZUMA-3 and ZUMA-4 trials. Blood 2016;128:2803.

109. Shah NN, Stetler-Stevenson M, Yuan CM, et al. Minimal residual disease negative complete remissions following anti-CD22 chimeric antigen receptor (CAR) in children and young adults with relapsed/refractory acute lymphoblastic leukemia (ALL). Blood 2016;128:650.

110. Kochenderfer JN, Dudley ME, Feldman SA, et al. B-cell depletion and remissions of malignancy along with cytokineassociated toxicity in a clinical trial of anti-CD19 chimeric-antigen-receptor-transduced T cells. Blood 2012;119:2709-20.

111. Sauter CS, Riviere I, Bernal Y, et al. Phase I trial of $19-28 \mathrm{z}$ chimeric antigen receptor modified $\mathrm{T}$ cells (19-28z CAR-T) post-high dose therapy and autologous stem cell transplant (HDT-ASCT) for relapsed and refractory (rel/ref) aggressive B-cell non-Hodgkin lymphoma (B-NHL). J Clin Oncol 2015; 33 (suppl; abstr 8515).

112. Zhang W, Wang Y, Guo Y, et al. Treatment of CD20-directed chimeric antigen receptor-modified $\mathrm{T}$ cells in patients with relapsed or refractory B-cell non-Hodgkin lymphoma: an early phase IIa trial report. Signal Transduct Target Ther 2016;1:1.

113. Wang Y, Zhang WY, Han QW, et al. Effective response and delayed toxicities of refractory advanced diffuse large B-cell lymphoma treated by CD20-directed chimeric antigen receptor-modified T cells. Clin Immunol 2014;155:160-75.

114. Turtle CJ, Hanafi L-A, Li D, et al. CD19 CAR-T cells are highly effective in ibrutinib-refractory chronic lymphocytic leukemia. Blood 2016;128:56.

115. Turtle CJ, Hanafi LA, Berger C, et al. Immunotherapy of nonHodgkin's lymphoma with a defined ratio of $\mathrm{CD} 8+$ and CD4 + CD19-specific chimeric antigen receptor-modified $\mathrm{T}$ cells. Sci Transl Med 2016;8:355ra116.

116. Turtle CJ, Berger C, Sommermeyer D, et al. Anti-CD19 chimeric antigen receptor-modified $\mathrm{T}$ cell Therapy for B Cell nonHodgkin lymphoma and chronic lymphocytic leukemia: fludarabine and cyclophosphamide lymphodepletion improves in vivo expansion and persistence of CAR-T cells and clinical outcomes. Blood 2015;126:184.

117. Geyer MB, Park JH, Riviere I, et al. Implications of concurrent ibrutinib therapy on CAR T-cell manufacturing and phenotype and on clinical outcomes following CD19-targeted CAR T-cell 
administration in adults with relapsed/refractory CLL. Blood 2016;128:58.

118. Neelapu SS, Locke FL, Bartlett NL, et al. A phase 2 multicenter trial of KTE-C19 (anti-CD19 CAR T cells) in patients with chemorefractory primary mediastinal B-Cell lymphoma (PMBCL) and transformed follicular lymphoma (TFL): interim results from ZUMA-1. Blood 2016;128:998.

119. Abramson JS, Palomba L, Gordon LI, et al. Transcend NHL 001: immunotherapy with the CD19-directed CAR T-cell product JCAR017 results in high complete response rates in relapsed or refractory B-Cell non-Hodgkin lymphoma. Blood 2016;128:4192.

120. Kochenderfer JN, Somerville RP, Lu T, et al. Anti-CD19 chimeric antigen receptor $\mathrm{T}$ cells preceded by low-dose chemotherapy to induce remissions of advanced lymphoma. J Clin Oncol 2016;34 (suppl; abstr LBA3010).

121. Brudno JN, Shi V, Stroncek D, et al. T cells expressing a novel fully-human anti-CD19 chimeric antigen receptor induce remissions of advanced lymphoma in a first-in-humans clinical trial. Blood 2016;128:999.

122. Porter DL, Frey NV, Melenhorst JJ, et al. Randomized, phase II dose optimization study of chimeric antigen receptor modified $\mathrm{T}$ cells directed against CD19 (CTL019) in patients with relapsed, refractory CLL. Blood 2014;124:1982.

123. Porter DL, Frey N, Melenhorst JJ, et al. Randomized, phase II dose optimization study of chimeric antigen receptor (CAR) modified $\mathrm{T}$ cells directed against CD19 in patients (pts) with relapsed, refractory (R/R) CLL. J Clin Oncol 2016;34 (suppl; abstr 3009).

124. Schuster SJ, Svoboda J, Nasta S, et al. Phase IIa trial of chimeric antigen receptor modified $\mathrm{T}$ cells directed against CD19 (CTL019) in patients with relapsed or refractory CD19+ lymphomas. J Clin Oncol 2015;33 (suppl; abstr 8516).

125. Schuster SJ, Svoboda J, Nasta SD, et al. Treatment with chimeric antigen receptor modified $\mathrm{T}$ cells directed against CD19 (CTL019) results in durable remissions in patients with relapsed or refractory diffuse large B cell lymphomas of germinal center and non-germinal center origin, "Double Hit" diffuse large B cell lymphomas, and transformed follicular to diffuse large B cell lymphomas. Blood 2016;128:3026.

126. Chong EA, Svoboda J, Nasta SD, et al. Chimeric antigen receptor modified T cells directed against CD19 (CTL019) in patients with poor prognosis, relapsed or refractory $\mathrm{CD} 19+$ follicular lymphoma: prolonged remissions relative to antecedent therapy. Blood 2016;128:1100.

127. Schuster SJ, Svoboda J, Dwivedy Nasta S, et al. Phase IIa trial of chimeric antigen receptor modified $\mathrm{T}$ cells directed against CD19 (CTL019) in patients with relapsed or refractory CD19+ lymphomas. Blood 2014;124:3087.

128. Locke FL, Neelapu SS, Bartlett NL, et al. Phase 1 results of ZUMA-1: a multicenter study of KTE-C19 anti-CD19 CAR T cell therapy in refractory aggressive lymphoma. Mol Ther 2017:25:285-95.

129. Locke FL, Neelapu SS, Bartlett NL, et al. Phase 1 clinical results of the ZUMA-1 (KTE-C19-101) study: a phase 1-2 multi-center study evaluating the safety and efficacy of anti-CD19 CAR T cells (KTE-C19) in subjects with refractory aggressive nonHodgkin lymphoma (NHL). Blood 2015;126:3991.

130. Gardner R, Wu D, Cherian S, et al. Acquisition of a CD19negative myeloid phenotype allows immune escape of MLLrearranged B-ALL from CD19 CAR-T-cell therapy. Blood 2016;127:2406-10.

131. Deniger DC, Yu J, Huls MH, et al. Sleeping beauty transposition of chimeric antigen receptors targeting receptor tyrosine kinaselike orphan Receptor-1 (ROR1) into diverse memory T-cell populations. PLoS One 2015;10:e0128151.
132. Fred Hutchinson Cancer Research Center. Genetically Modified T-Cell Therapy in Treating Patients With Advanced ROR1+ Malignancies. In: ClinicalTrials.gov [Internet]. Bethesda (MD): National Library of Medicine (US). Available at: https://clinicaltrials.gov/ct2/show/NCT02706392; 2000. Accessed March 7, 2017. NLM Identifier: NCT02706392.

133. M.D. Anderson Cancer Center. Autologous ROR1R-CAR-T Cells for Chronic Lymphocytic Leukemia (CLL). In: ClinicalTrials.gov [Internet]. Bethesda (MD): National Library of Medicine (US). Available at: https://clinicaltrials.gov/ct2/show/ NCT02194374; 2000. Accessed March 7, 2017. NLM Identifier: NCT02194374.

134. Jackson HJ, Rafiq S, Brentjens RJ. Driving CAR T-cells forward. Nat Rev Clin Oncol 2016;13:370-83.

135. Fesnak AD, June CH, Levine BL. Engineered T cells: the promise and challenges of cancer immunotherapy. Nat Rev Cancer 2016;16:566-81.

136. Wilkie S, van Schalkwyk MC, Hobbs S, et al. Dual targeting of ErbB2 and MUC1 in breast cancer using chimeric antigen receptors engineered to provide complementary signaling. J Clin Immunol 2012;32:1059-70.

137. Fedorov VD, Themeli M, Sadelain M. PD-1- and CTLA-4-based inhibitory chimeric antigen receptors (iCARs) divert off-target immunotherapy responses. Sci Transl Med 2013;5:215ra172.

138. Roybal KT, Rupp LJ, Morsut L, et al. Precision tumor Recognition by $\mathrm{T}$ Cells with combinatorial antigen-sensing circuits. Cell 2016;164:770-9.

139. Kloss CC, Condomines M, Cartellieri M, Bachmann M, Sadelain M. Combinatorial antigen recognition with balanced signaling promotes selective tumor eradication by engineered T cells. Nat Biotechnol 2013;31:71-5.

140. Ruella M, Maus MV. Catch me if you can: leukemia escape after CD19-directed T cell immunotherapies. Comput Struct Biotechnol J 2016;14:357-62.

141. Poirot L, Philip B, Schiffer-Mannioui C, et al. Multiplex genomeedited T-cell manufacturing platform for "Off-the-Shelf" adoptive T-cell immunotherapies. Cancer Res 2015;75:3853-64.

142. Torikai H, Reik A, Liu PQ, et al. A foundation for universal Tcell based immunotherapy: $\mathrm{T}$ cells engineered to express a CD19-specific chimeric-antigen-receptor and eliminate expression of endogenous TCR. Blood 2012;119:5697-705.

143. Valton J, Guyot V, Marechal A, et al. A multidrug-resistant engineered CAR T cell for allogeneic combination immunotherapy. Mol Ther 2015;23:1507-18.

144. Osborn MJ, Webber BR, Knipping F, et al. Evaluation of TCR gene editing achieved by TALENs, CRISPR/Cas9, and megaTAL nucleases. Mol Ther 2016;24:570-81.

145. Institut de Recherches Internationales Servier. Study of UCART 19 in Pediatric Patients With Relapsed/Refractory B Acute Lymphoblastic Leukemia (PALL). In: ClinicalTrials.gov [Internet]. Bethesda (MD): National Library of Medicine (US); 2000 Available at: https://clinicaltrials.gov/ct2/show/NCT02808442; 2000. Accessed March 17, 2017. NLM Identifier: NCT02808442.

146. Servier. Dose Escalation Study to Evaluate the Safety, Tolerability and Biological Activity of a Single Dose of UCART19 in Patients With Relapsed/Refractory (R/R) B-cell Acute Lymphoblastic Leukaemia (ALL) and Chronic Lymphocytic Leukaemia (CLL) (CALM). In: ClinicalTrials.gov [Internet]. Bethesda (MD): National Library of Medicine (US); 2000. Available at: https://clinicaltrials.gov/ct2/show/NCT02746952; 2000. Accessed March 17, 2017. NLM Identifier: NCT02746952.

147. Khalil DN, Smith EL, Brentjens RJ, Wolchok JD. The future of cancer treatment: immunomodulation, CARs and combination immunotherapy. Nat Rev Clin Oncol 2016;13:273-90. 